\title{
Concentration-dependent effects of sodium cholate and deoxycholate bile salts on breast cancer cells proliferation and survival
}

\author{
Yamila B. Gándola ${ }^{1,2} \cdot$ Camila Fontana $^{2} \cdot$ Mariana A. Bojorge $^{2} \cdot$ Tania T. Luschnat $^{2} \cdot$ Marcela A. Moretton $^{1,3}$. \\ Diego A. Chiapetta ${ }^{1,3} \cdot$ Sandra V. Verstraeten ${ }^{1,2} \cdot$ Lorena González $^{1,2}$ (i)
}

Received: 19 December 2019 / Accepted: 6 April 2020

○) Springer Nature B.V. 2020

\begin{abstract}
Bile acids (BAs) are bioactive molecules that have potential therapeutic interest and their derived salts are used in several pharmaceutical systems. BAs have been associated with tumorigenesis of several tissues including the mammary tissue. Therefore, it is crucial to characterize their effects on cancer cells. The objective of this work was to analyse the molecular and cellular effects of the bile salts sodium cholate and sodium deoxycholate on epithelial breast cancer cell lines. Bile salts (BSs) effects over breast cancer cells viability and proliferation were assessed by MTS and BrdU assays, respectively. Activation of cell signaling mediators was determined by immunobloting. Microscopy was used to analyze cell migration, and cellular and nuclear morphology. Interference of membrane fluidity was studied by generalized polarization and fluorescence anisotropy. BSs preparations were characterized by transmission electron microscopy and dynamic light scattering. Sodium cholate and sodium deoxycholate had dual effects on cell viability, increasing it at the lower concentrations assessed and decreasing it at the highest ones. The increase of cell viability was associated with the promotion of AKT phosphorylation and cyclin D1 expression. High concentrations of bile salts induced apoptosis as well as sustained activation of p38 and AKT. In addition, they affected cell membrane fluidity but not significant effects on cell migration were observed. In conclusion, bile salts have concentration-dependent effects on breast cancer cells, promoting cell proliferation at physiological levels and being cytotoxic at supraphysiological ones. Their effects were associated with the activation of kinases involved in cell signalling.
\end{abstract}

Keywords Bile acids and salts · Cell signaling · Breast cancer cells · Apoptosis · Cancer · Protein phosphorylation · Receptors $\cdot$ Plasma membrane

Abbreviations

AKT Protein kinase B

Electronic supplementary material The online version of this BrdU Bromodeoxyuridine article (https://doi.org/10.1007/s11033-020-05442-2) contains supplementary material, which is available to authorized users.

Lorena González

lgonza74@yahoo.com.ar; lgonzalez@qb.ffyb.uba.ar

Yamila B. Gándola

yamigandola@gmail.com

Camila Fontana

caamu._@live.com

Mariana A. Bojorge

mariana.bojorge.168@gmail.com

Tania T. Luschnat

tania.lus@hotmail.com

Marcela A. Moretton

marce_more126@hotmail.com

Diego A. Chiapetta

diegochiappetta@yahoo.com.ar
Sandra V. Verstraeten

verstraeten@ffyb.uba.ar

1 Consejo Nacional de Investigaciones Científicas y Técnicas (CONICET), Instituto de Química y Fisicoquímica Biológicas (IQUIFIB), Facultad de Farmacia y Bioquímica, Universidad de Buenos Aires, Buenos Aires, Argentina

2 Departamento de Química Biológica, Facultad de Farmacia y Bioquímica, Universidad de Buenos Aires, Junín 956 (1113), Buenos Aires, Argentina

3 Facultad de Farmacia y Bioquímica, Departamento de Tecnología Farmacéutica, Universidad de Buenos Aires, Buenos Aires, Argentina 
ERK 1/2 Extracellular signal-regulated protein kinases 1 and 2

FXR $\alpha \quad$ Farnesoid X receptor alpha

GP Generalalized polarization

JNK Jun amino-terminal kinase

MAPKS Mitogen-activated protein kinases

MTS 3-(4,5-Dimethylthiazol-2-yl)-5-(3carboxymethoxyphenyl)-2-(4-sulfophenyl)2H-tetrazolium

PARP Poly ADP-ribose polymerase

PI3K Phosphatidylinositide 3-kinases

\section{Introduction}

BAs are amphipathic molecules synthesized in the hepatocytes from cholesterol and through a series of enzymatic reactions [1]. They exist as ionized bile salts (BSs) under physiological conditions. BAs are actively transported from the apical side of hepatocytes to bile canaliculi and are stored in the gall bladder along with other bile constituents. Upon food intake, bile is secreted into the small intestine where these molecules form mixed micelles with cholesterol and phospholipids. Most of the BAs are reabsorbed by the enterocytes in the gut and recycled back to the liver via the portal vein in a process called enterohepatic circulation. BAs are mainly involved in fat solubilization and absorption in the gut, facilitating the uptake of fat-soluble vitamins. However, many other functions have been described recently. BAs are not only detergents, but important signaling molecules due to their capacity to interact with various receptors, including nuclear and $\mathrm{G}$ protein-coupled receptors [2]. Consequently, BAs affect different biological processes, including BA and lipid metabolism, glucose homeostasis, energy expenditure, gut motility, and immune cell function, among others [3].

Because of their characteristic structure and their emulsifying and solubilizing properties, BAs are used in pharmaceutical industry as delivery systems for medical and cosmetic products $[4,5]$. For example, BAs are used to improve the hydrophilicity of water-insoluble drugs such as amphotericin B and resveratrol [6,7], and as permeation enhancers in topical dosage forms [8]. BA-containing vesicles-or bilosomes-have been developed as delivery systems for oral administration of poorly water-soluble drugs and peptide/protein-based therapeutics or vaccines, because they stabilize these compounds against the acidic milieu and enzymes present in the gastrointestinal tract $[9,10]$. The inclusion of BAs in several nanocarriers helped to overcome major obstacles of drug delivery to specific targets $[4,11$, 12]. For example, the conjugation of hydrophilic and biodegradable polymers to BAs is a promising strategy to deliver anti-tumoral drugs to their site of action $[11,13]$.
Despite BAs used in pharmaceutical systems and their therapeutic potential, since the 1940s certain BAs have been proposed to be cancer promoters [14]. Supporting that, several studies associated increased enterohepatic, circulating and/or plasma levels of BAs with cancer promotion both in animal models and in humans [15-18]. Among others, high BA exposure has been associated with increased incidence of laryngopharyngeal tract, esophagus, stomach, pancreas, small intestine, colon and breast cancers $[18,19]$.

The mechanisms underlying the promotion of carcinogenesis in the gastrointestinal tract upon BAs exposure would involve the disruption of cell and/or organelle membranes, the alteration of cell signaling pathways and gene expression. BAs are capable of disrupting lipid bilayers of the epithelium of the gastrointestinal tract and thus alter their permeability. Therefore, potentially harmful substances, such as food carcinogens, could enter epithelial cells. Upon the exposure to high BA concentrations, reactive oxygen (ROS) and nitrogen (RNS) species are generated rapidly [20, 21], which could result in DNA damage and increased mutation frequency [17]. It might be expected that recurrent exposure of cells to high concentrations of cytotoxic BAs would allow the selective growth of cells resistant to BA-induced apoptosis [17, 18]. Tissular enrichment in those cells, and the activation of mitogenic signaling cascades caused by the BAs [2, 22, 23] could result in tumor generation.

Epidemiological studies have demonstrated that incidence rates of colon and breast cancers are highly correlated with each other, and with the regular consumption of high fat and animal protein diets [24].The plasma bile acid profile has shown to reflect the intestinal bile acid profile [25] and traffic of bile acids from plasma to the mammary gland has been reported [26]. In accordance, breast cancer incidence has been described to increase in women that have undergone cholecystectomy [27]. Moreover, plasma deoxycholic acid concentration was described to be increased in postmenopausal women with newly diagnosed breast cancer [19] and breast cyst fluid contained very high BAs concentrations $[28,29]$.The molecular mechanisms underlying the possible carcinogenic action of BAs in breast tissue are not clear, but they could involve alterations on estrogen receptordependent signaling [30], and the activation of farnesoid $X$ (FXR $\alpha$ ) and/or transmembrane G-protein-coupled (TGR5) receptors [2]. The capacity of those and other receptors to bind BAs will ultimately depend on the chemical properties of the individual BAs, that will determine their affinity for the receptors [31].

Considering the potential roles of BAs in the promotion of breast cancer, the lack of knowledge about their mechanism of action in breast tissues, and the wide use of BAs in pharmaceutical formulations, the aim of the present work was to analyze the potential proliferative or cytotoxic roles of naturally occurring bile salts of cholic (SC) and 
deoxycholic (SDC) acids in breast cancer cells. Experiments were carried out spanning a broad range of BSs concentrations (physiologic and supra-physiological), and the possible participation of signaling pathways involving kinases to mediate BSs cellular effects were investigated.

\section{Methods}

\section{Reagents and materials}

Sodium cholate (SC) and sodium deoxycholate hydrate (SDC), Trizma base, HEPES, Tween20, Triton X-100, sodium dodecyl sulfate (SDS), glycine, ammonium persulfate, aprotinin, phenylmethylsulfonylfluoride (PMSF), sodium orthovanadate, 2-mercaptoethanol, Hoechst 33,258, cell proliferation BrdU ELISA kit, and BSA-fraction V were obtained from Sigma Chemical Co. (St. Louis, MO, USA). Fetal bovine serum was from Gibco ${ }^{\mathrm{TM}}$. PVDF membranes, high performance chemiluminescence film, and enhanced chemiluminescence (ECL) Plus are from Amersham Biosciences (GE Healthcare, Piscataway, NY, USA). Acrylamide, bis-acrylamide, and TEMED were obtained from Bio-Rad Laboratories (Hercules, CA, USA). Antibodies against p38, phospho-p38, cyclin D1, actin, and HRP-conjugated secondary antibodies were purchased from Santa Cruz Biotechnology Laboratories (Santa Cruz, CA, USA). Antibodies against PARP, AKT, phosphoAKT, p44/42 MAP kinase (ERK1/2), and phospho-p44/42 MAP kinase Thr202/Tyr204 were from Cell Signaling Technology Inc. (Beverly, MA, USA). Gentamycin, L-glutamine,6-(9-anthroyloxy) stearic acid (6-AS), 12-(9-anthroyloxy) stearic acid (12-AS), 16-(9-anthroyloxy) palmitic acid (16-AP), 1-(4-trimethylammoniumphenyl)-6-phenyl-1,3,5-hexatriene p-toluenesulphonate (TMA-DPH) and 3-(4-(6-phenyl)1,3,5-hexatrienyl) phenylpropionic acid (PA-DPH), and 6-dodecanoyl-2-dimethylamino-naphthalene (Laurdan) were purchased from Invitrogen/Molecular Probes Inc. (Eugene, OR, USA). Dulbecco's Modified Eagle Medium (DMEM) and bicinchoninic acid (BCA) protein assay kit were obtained from Thermo Scientific, Pierce Protein Research Products (Rockford, IL, USA). CellTiter 96 aqueous nonradioactive cell proliferation assay was from Promega (Madison, WI, USA). 96-, 24- and 6-well plates were acquired from Corning Costar (Fisher Scientific, New York, USA).

\section{Cell culture}

Human breast cancer MCF-7 and MDA-MB-231 cell lines were obtained from the American Type Culture Collection (ATCC, Rockville, MD, USA). Cells were maintained in Dulbecco's minimum essential medium (DMEM) supplemented with $10 \%$ fetal bovine serum (FBS), $50 \mu \mathrm{g} / \mathrm{mL}$ gentamycin, and $2 \mathrm{mM} \mathrm{L}$-glutamine. Cells were cultured in $75 \mathrm{~cm}^{2}$ culture flasks at $37{ }^{\circ} \mathrm{C}$ in a humidified atmosphere of $5 \% \mathrm{CO}_{2}$. Unless otherwise indicated, all incubations were performed in the same humidified $5 \% \mathrm{CO}_{2}$ atmosphere.

\section{Cell viability assay}

Mitochondrial functionality was determined spectrophotometrically from the reduction of tetrazolium salt (MTS) to formazan, using the CellTiter 96 aqueous nonradioactive cell proliferation assay. Cells $(10,000$ cells/well) were seeded on 96-well plates and incubated overnight at $37^{\circ} \mathrm{C}$ to allow cell attachment. Culture media was discarded and $100 \mu \mathrm{l}$ of serum-free medium containing the BSs at different concentrations $(0.025-2 \mathrm{mM})$ was added. After incubation for 24 or $48 \mathrm{~h}$, cells were added with $20 \mu \mathrm{l}$ of MTS solution and further incubated for $2 \mathrm{~h}$ at $37^{\circ} \mathrm{C}$. Absorbance was recorded at $492 \mathrm{~nm}$ in a microplate reader (Sunrise, Tecan Austria $\mathrm{GmbH}$ ). At least four independent experiments were performed; each experimental point was assayed in triplicate. Cells not exposed to the bile salts served as controls in each experiment and viability was expressed as the percentage of the value recorded in untreated control cells.

\section{Cell treatment and immunoblotting}

Cells (300,000 cells/well) were seeded on 6-well plates and allowed to attach for $24 \mathrm{~h}$. Afterwards, the culture medium was replaced by serum-free DMEM and BSs were added at the concentrations indicated for the individual experiments. Cells were further incubated at $37{ }^{\circ} \mathrm{C}$ for various periods of time, in a $5 \% \mathrm{CO}_{2}$ atmosphere. After incubation, cells were washed with phosphate saline buffer (PBS) and dishes were kept at $-80^{\circ} \mathrm{C}$ until cell solubilization. Cells were homogenized at $4{ }^{\circ} \mathrm{C}$ in $0.1 \mathrm{M}$ Hepes buffer (pH 7.0) containing $1 \%$ (v/v) Triton-X, $0.1 \mathrm{M}$ sodium pyrophosphate, $0.1 \mathrm{M}$ sodium fluoride, $0.01 \mathrm{M}$ EDTA, $0.01 \mathrm{M}$ sodium vanadate, 0.002 M PMSF, and 0.035 units $/ \mathrm{mL}$ aprotinin. Cell homogenates were centrifuged at $15,000 \times g$ for $40 \mathrm{~min}$ at $4{ }^{\circ} \mathrm{C}$ to remove insoluble material. Protein concentration of supernatants was determined by the BCA protein assay kit. Aliquots of solubilized cells containing equal amounts of proteins were added with Laemmli buffer, boiled for $5 \mathrm{~min}$, and stored at $-20{ }^{\circ} \mathrm{C}$ until their use. Samples were resolved by SDSPAGE, transferred to PVDF membranes, and proteins of interest were analyzed as described previously [32].

\section{Hoechst staining}

Cells (50,000 cells/well) were seeded on glass coverslips placed in 24-well plates, allowed to attach for $24 \mathrm{~h}$. Samples were added with SC ( $2 \mathrm{mM})$ or SDC $(1 \mathrm{mM})$ in serum-free medium and further incubated at $37{ }^{\circ} \mathrm{C}$ for $24 \mathrm{~h}$, in a $5 \% \mathrm{CO}_{2}$ 
atmosphere. After incubation, cells were washed twice with pre-warmed PBS ( $\mathrm{pH} 7.0)$ and fixed with $2 \%(\mathrm{w} / \mathrm{v})$ formaldehyde in PBS for 10 min at room temperature. After three washes with PBS (5 min each), fixed cells were incubated for $10 \mathrm{~min}$ at room temperature in the presence of the fluorescent probe Hoechst 33,258 $(2 \mu \mathrm{g} / \mathrm{mL})$, washed 3 times with PBS, mounted on glass slides, and florescence stained cells were observed in a Leica DM2000 (Leica-Microsystems, Germany) epifluorescence microscope, with a 40X objective (numerical aperture $=0.65$ ). At least 10 fields were examined, and representative images were photographed.

\section{BrdU incorporation assay}

Cell proliferation was determined by measuring BrdU incorporation. Cells (10,000 cells/well) were seeded in 96-well culture plates and allowed to attach for $24 \mathrm{~h}$. Samples were added with the BAs in $100 \mu \mathrm{l}$ of serum-free medium, and further incubated at $37^{\circ} \mathrm{C}$ for $30 \mathrm{~h}$ in a $5 \% \mathrm{CO}_{2}$ atmosphere. At that time point, $0.01 \mu \mathrm{M}$ BrdU was added to the samples, and cells were further incubated for $18 \mathrm{~h}$, to complete $48 \mathrm{~h}$ of exposure to the BSs. Cell cultures were rinsed with prewarmed PBS (pH 7.0), and processed according the manufacturer's instructions. Samples were run in triplicates for each treatment. Results were expressed as the percentage respect of the value recorded in untreated control cells.

\section{In vitro wound healing assay}

Cells were cultured on 6-well plates until reaching - 90\% confluence. Cell layer was scratched with a sterile $200 \mu \mathrm{l}$ pipette tip and detached cells were removed. BSs dissolved in serum-free DMEM were added to the cells. For each treatment at least 5 scratched fields were photographed immediately, and after 24 and $48 \mathrm{~h}$ of incubation. Images were acquired with a Nikon TE300 microscope (Nikon Instruments Inc., Japan) equipped with a CMOS camera. Cell migration was evaluated by measuring the wounded area with the open-access software ImageJ [33].

\section{Evaluation of plasma membrane fluidity and hydration}

Cells (10,000 cells/well) were seeded in 96-well culture plates apt for fluorescence measurement (Porvair Sciences Limited, Wales, UK) and allowed to attach for $24 \mathrm{~h}$. Culture medium was replaced with serum-free DMEM containing $\mathrm{SC}(0.01$ or $2 \mathrm{mM})$ or SDC $(0.005$ or $1 \mathrm{mM})$, and cells were incubated at $37^{\circ} \mathrm{C}$ for further $24 \mathrm{~h}$. At the end of incubation, samples were washed three times with pre-warmed PBS and incubated at $37^{\circ} \mathrm{C}$ for $15 \mathrm{~min}$ in the presence of the probes indicated below.
To assess the effect of SC and SDC on the fluidity at different depths of the membrane, samples were added with $0.5 \mu \mathrm{M}$ of the probes 6-AS, 12-AS or 16-AP [34], and the fluorescence anisotropy of the probes at $37^{\circ} \mathrm{C}$ ( $\lambda$ excitation: $384 \mathrm{~nm}$; $\lambda$ emission: $435 \mathrm{~nm}$ ) was recorded in a Flex Station 3 spectrofluorometer (Molecular Devices LLC, Sunnyvale, CA, USA).

The effects of SC and SDC on the fluidity of the exofacial and cytoplasmic hemilayers of the plasma membrane were evaluated using the fluorescent probes PA-DPH and TMADPH, respectively as described previously [35]. For that, samples were added with $0.5 \mu \mathrm{M}$ of the probes TMA-DPH or PA-DPH, and fluorescence anisotropy of the probes at 37 ${ }^{\circ} \mathrm{C}$ was recorded at $450 \mathrm{~nm}$ ( $\lambda$ excitation: $365 \mathrm{~nm}$ ).

The effects of SC and SDC on membrane hydration at the phospholipid glycerol backbone level were evaluated using the fluorescent probe Laurdan [34-36]. For that, samples were added with $0.5 \mu \mathrm{M}$ Laurdan, and the generalized polarization corresponding to the excitation spectra (GPexc) at $37^{\circ} \mathrm{C}$ was calculated as:

GPexc $=\frac{I_{430 \mathrm{~nm}}-I_{480 \mathrm{~nm}}}{I_{430 \mathrm{~nm}}+I_{480 \mathrm{~nm}}}$

where $\mathrm{I}_{430 \mathrm{~nm}}$ and $\mathrm{I}_{480 \mathrm{~nm}}$ are the fluorescence intensities at 430 and $480 \mathrm{~nm}$ ( $\lambda$ excitation: $350 \mathrm{~nm}$ ), respectively.

Stock solutions of the fluorescent probes were prepared in DMSO. The final concentration of DMSO in the samples was kept lower than $0.05 \%(\mathrm{v} / \mathrm{v})$ to avoid alterations in membrane properties [34].

\section{BSs characterization}

BSs stock solutions were prepared in distilled water at room temperature, filtered through $0.22 \mu \mathrm{m}$ membranes, and immediately stored in $-20^{\circ} \mathrm{C}$ until their use. The average hydrodynamic diameter $(\mathrm{Dh})$ and the size distribution of the formulations were determined by dynamic light scattering (DLS; Zetasizer Nano-ZSP, Malvern Instruments, UK) at $25{ }^{\circ} \mathrm{C}$. Measurements were conducted at a scattering angle of $173^{\circ}$ to the incident beam. Aliquots of the samples were filtered through $0.45 \mu \mathrm{m}$ acetate cellulose filters (Microclar, Argentina), and equilibrated at 25 ${ }^{\circ} \mathrm{C}$ for 5 min prior to the analysis. Instrument calibration was performed using standard latex nanoparticles (Malvern Instruments, UK). Results were expressed as the mean \pm SD of at least five independent measurements. BA formulations were visualized using transmission electron microscopy (TEM, Zeiss EM109T TEM apparatus, Carl Zeiss Microscopy GmbH, Germany) at the LANAIS-MIE (UBA-CONICET, Argentina) electron microcopy facilities. Samples $(5 \mu \mathrm{l})$ were placed onto a grid covered with 
Fomvar film where the excess was removed after $30 \mathrm{~s}$. Then, uranil acetate $(0.6 \mu \mathrm{g} / \mathrm{ml}$ in distilled water $)$ was added to the samples and the excess was removed $(30 \mathrm{~s})$. Finally, distilled water $(5 \mu \mathrm{l})$ was added for another $30 \mathrm{~s}$, removed and samples were dried in a silica gel container and analyzed.

\section{Statistical analysis}

Experiments were performed analyzing in parallel the effects measured in BA- and vehicle (control)-treated cells. Statistical analyses were performed by ANOVA followed by Dunnett comparison test using the GraphPad Prism 6 (GraphPad Software Inc., San Diego, CA, USA). A probability (p) value $<0.05$ was considered statistically significant. Unless indicated otherwise, results are shown as the mean \pm SEM of the indicated number ( $n$ ) of individual experiments. Statistical significances are indicated in the figures using the following code: $* \mathrm{p} \leq 0.05, * * \mathrm{p} \leq 0.01, * * * \mathrm{p} \leq 0.001$ and $* * * * \mathrm{p} \leq 0.0001$.
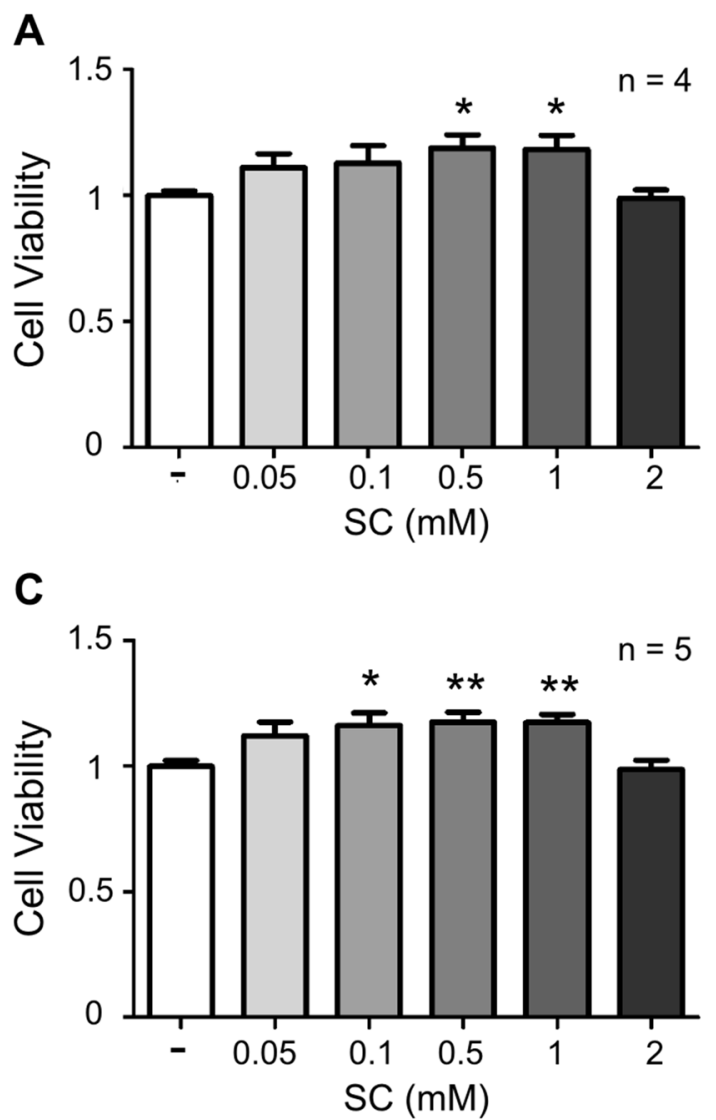

Fig. 1 BSs affect cell viability. MCF-7 cells were incubated for (a and b) $24 \mathrm{~h}$ or (c and d) $48 \mathrm{~h}$ in the presence of (a and c) $0.05-2 \mathrm{mM}$ $\mathrm{SC}$ or (b and d) $0.025-1 \mathrm{mM}$ SDC. After incubation, cell viability

\section{Results}

\section{Effects of BSs on cell viability}

To understand the effects of natural BSs on breast cancer cells, the viability of MFC-7 cells was determined upon their incubation for $24 \mathrm{~h}$ (Fig. 1a, b) or $48 \mathrm{~h}$ (Fig. 1c, d) with SC or SDC, covering a wide range of concentrations ( 0.025 to $2 \mathrm{mM})$. Although concentrations of bile acids in human breast tumors are about 10-50 $\mu \mathrm{M}$ [37-39], higher SC and SDC doses were probed attending to their use in pharmaceutical formulations, and in order to have a better understanding of their possible effects over breast tissue. Experiments were performed in the absence of serum to prevent the incorporation of the BSs into lipoproteins and to avoid cell stimulation by growth factors from serum. Results would indicate a modest increase in the viability and/or mitochondrial functionality of cells incubated with SC up to $1 \mathrm{mM}$ concentration or with SDC up to $0.25 \mathrm{mM}$ concentration. Significant cytotoxic effects were observed at 24 and $48 \mathrm{~h}$ for the highest SDC

\section{B}
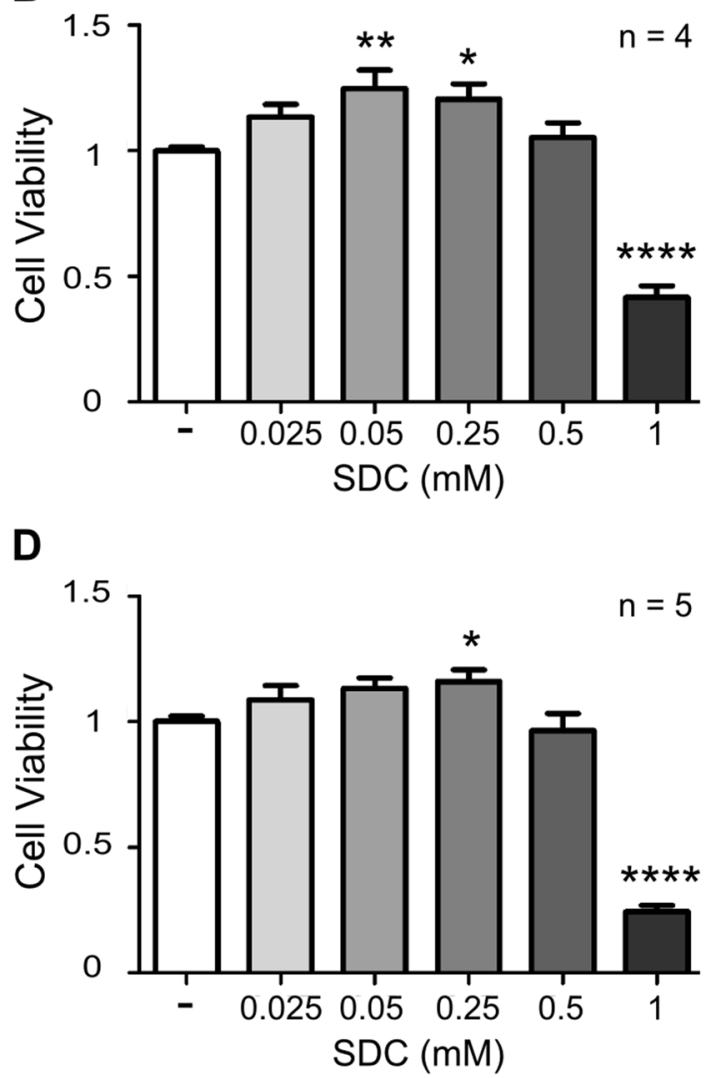

was evaluated, and results were expressed as the percentage of the value recorded in untreated control cells. Triplicates were run for each treatment 

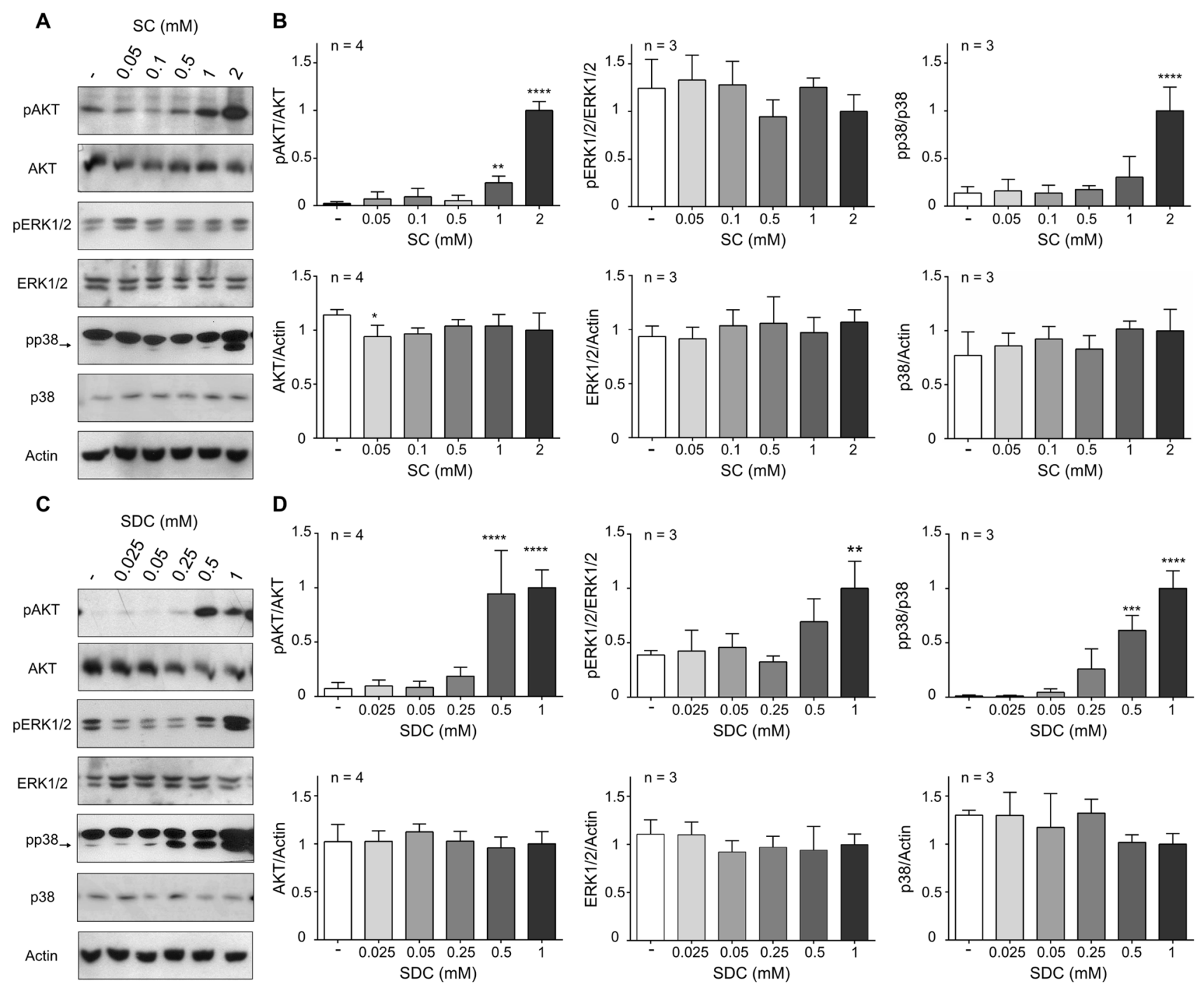

D
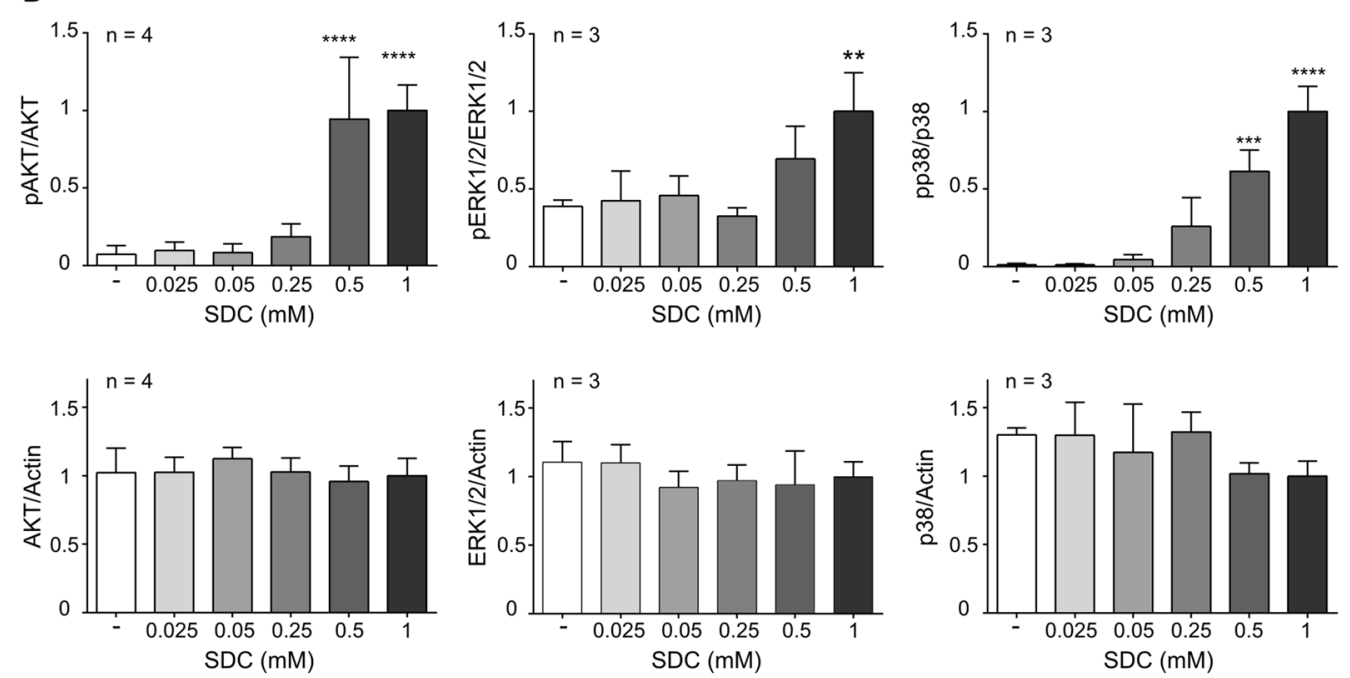

Fig. 2 BSs activate signaling kinases. MCF-7 cells were incubated for $24 \mathrm{~h}$ in the presence of $0.05-2 \mathrm{mM}$ SC or $0.025-1 \mathrm{mM}$ SDC. Proteins were separated by SDS-PAGE and analysed by Western blot. a, c Representative immunoblots showing the expression of the phosphorylated species of AKT (pAKT), ERK1/2 (pERK1/2), p38 (pp38),

concentrations evaluated, as evidenced from the decrease in their capacity to metabolize MTS.

\section{Effects of BSs on signaling pathways involving kinases}

Considering the concentration-dependent effect of BSs on cell viability, the activation of signaling kinases involved in cell proliferation and survival were analyzed in MCF-7 cells, after cell exposure for $24 \mathrm{~h}$ to SC or SDC. AKT phosphorylation at Ser473, an activating residue, was increased after cell treatment with SC (1-2 mM) (Fig. 2a, b) or SDC $(0.5-1 \mathrm{mM})$ (Fig. 2c, d). In contrast, no significant induction of ERK1/2 phosphorylation was observed in cells exposed

and non-phosphorylated proteins from cells treated with a SC or c SDC. Actin expression was used as a loading control. b, d Quantification of protein phosphorylation and total content of the non-phosphorylated species. Results were relativized to the value recorded for $\mathbf{b}$ 2 mM SC- or d 1 mM SDC-treated cells

to $\mathrm{SC}$, but a significant increase in ERK1/2 phosphorylation was observed for the highest SDC concentration assessed (Fig. 2b, d). While SC increased p38 phosphorylation at the highest concentration evaluated, SDC increased p38 phosphorylation at $0.25,0.5 \mathrm{mM}$ and higher concentrations. SC and SDC did not affect AKT, ERK1/2 or p38 total contents in MCF-7 cells (Fig. 2).

The assessing of the kinetics of signaling molecules activation may be elusive, due to the variety of mechanisms and pathways involved. Thus, we next extended the analysis of AKT, ERK1/2 and p38 phosphorylation after cell treatment with the highest concentrations of BSs for $15 \mathrm{~min}$ to $24 \mathrm{~h}$ (Fig. 3). After $30 \mathrm{~min}$ of incubation with SDC (1 mM) and $2 \mathrm{~h}$ with SC ( $2 \mathrm{mM})$, both BSs increased significantly AKT 

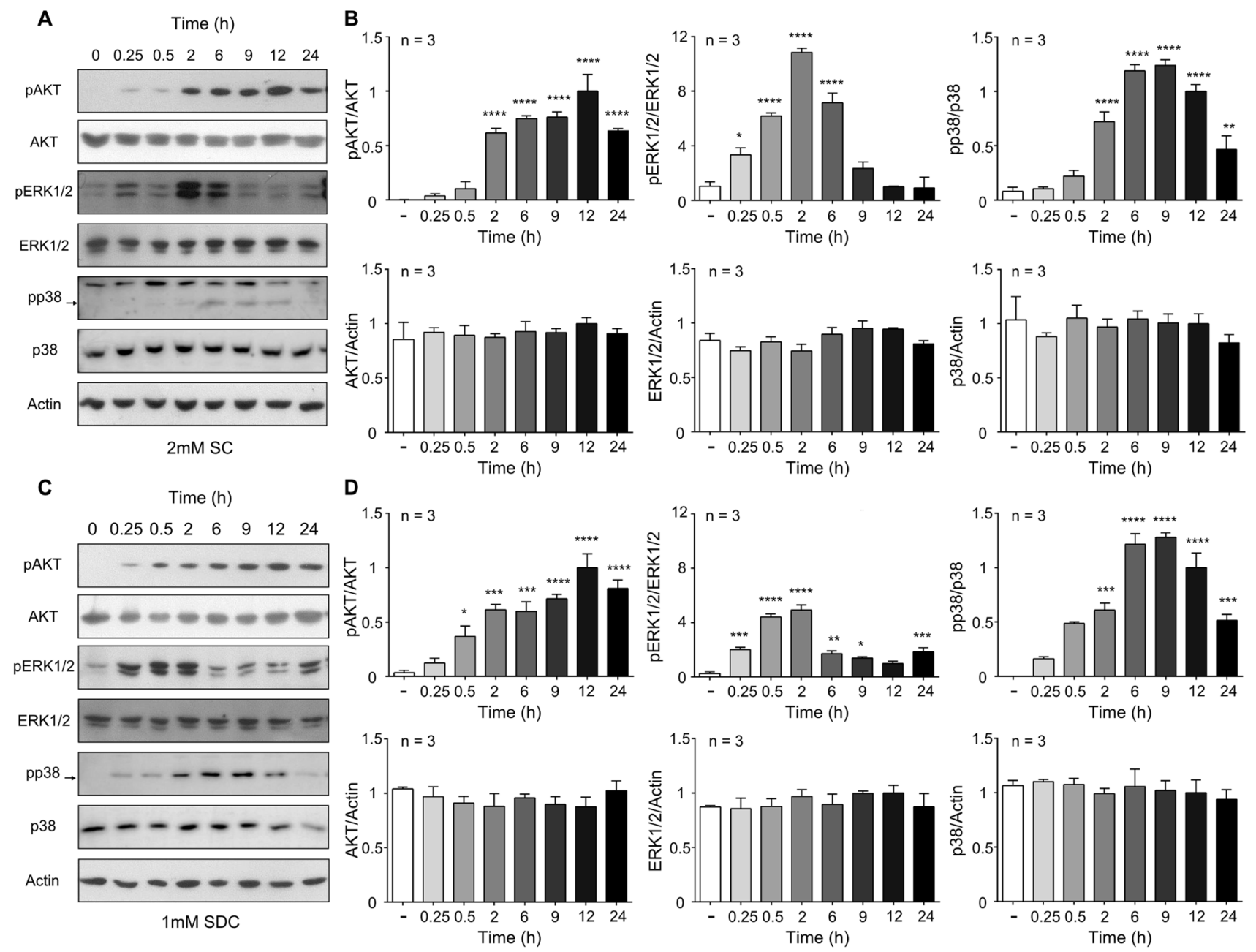

Fig. 3 BSs have similar kinetics of signaling pathways activation. MCF-7 cells were incubated with $2 \mathrm{mM} \mathrm{SC}$ or $1 \mathrm{mM} \mathrm{SDC}$ for different time periods $(0-24 \mathrm{~h})$. The activation of the kinases and total expression of the corresponding non-phosphorylated species were

analyzed as indicated in the legend to Fig. 2. a, c Representative Western blots. b, d Quantification of protein phosphorylation and total content, relativized to the value recorded at $12 \mathrm{~h}$ of incubation

phosphorylation which was sustained throughout the period evaluated (Fig. 3). The phosphorylation of p38 occurred later than that of AKT, being significant after $2 \mathrm{~h}$ of cell exposure to the BSs (Fig. 3). ERK1/2 had a different pattern of phosphorylation. In SC-treated cells, ERK1/2 was activated between $15 \mathrm{~min}$ and $6 \mathrm{~h}$ of incubation (Fig. 3a, b). In contrast, SDC-treated cells showed very high levels of phosphorylated ERK1/2 after 30 min and until $2 \mathrm{~h}$ of cell exposure, with a second wave of activation observed at $24 \mathrm{~h}$ of incubation (Fig. 3c, d). No differences in total AKT, ERK1/2 and p38 expression levels were observed throughout the period assessed (Fig. 3).

\section{Effects of BSs concentrations on the promotion of apoptosis}

AKT activation has been mainly associated with cell survival and proliferation, while p38 activation is triggered by stressing factors or apoptosis promoters. As it is described above, both kinases were activated after cell treatment with the highest concentrations of BSs tested, which resulted in decreased cell viability.

To determine if the decay in cell viability caused by the BSs was due to apoptosis, MCF-7 cells were incubated for $24 \mathrm{~h}$ in the presence of $2 \mathrm{mM} \mathrm{SC}$ or $1 \mathrm{mM} \mathrm{SDC}$ and visualized by bright field and fluorescence microscopies. As expected, SC (2 mM)- and SDC (1 mM)-treated samples contained lower amounts of cells than the controls and presented noticeable morphological alterations (Fig. 4a). Cells incubated with SC presented cell shrinkage and apoptotic 
A

Control
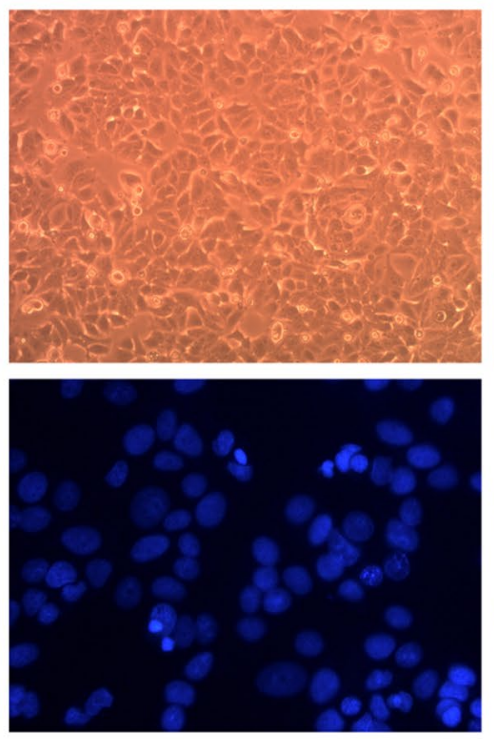

B

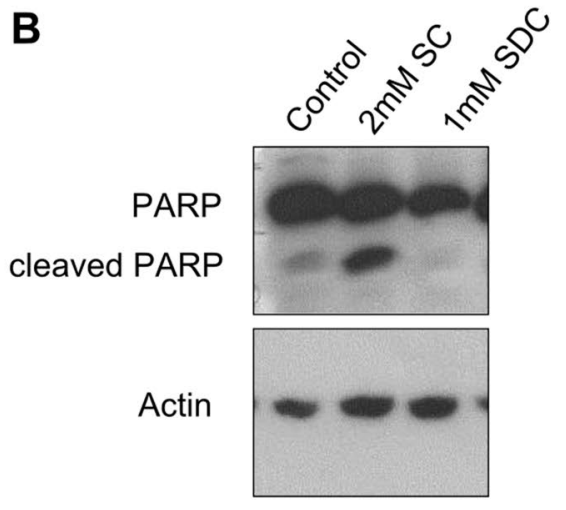

C

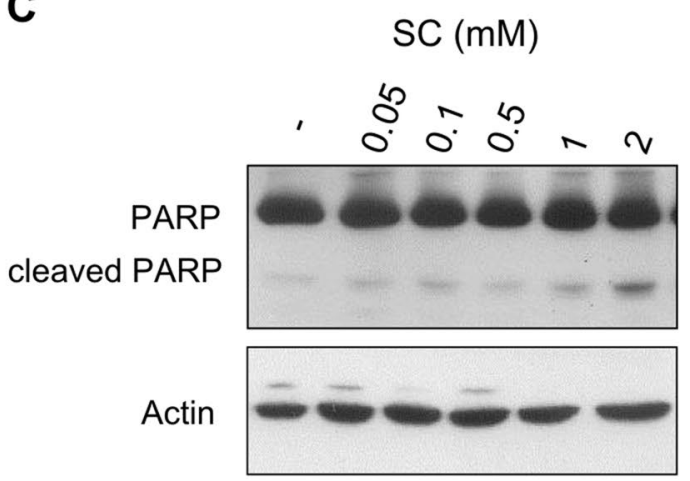

Fig. 4 BSs affect cell morphology and induce PARP cleavage. MCF-7 cells were incubated for $24 \mathrm{~h}$ in the presence of $2 \mathrm{mM} \mathrm{SC}$ or $1 \mathrm{mM}$ SDC. a Representative images of bright field (upper panel) and fluorescence microscopy images Hoechst-stained nuclei (lower panel). b Representative Western blot and quantification of PARP

bodies, whereas cells incubated with SDC showed mostly apoptotic bodies and cells were poorly attached to the surface (Fig. 4a). Nuclear staining of SC-treated cells revealed
$2 \mathrm{mM} \mathrm{SC}$

$1 \mathrm{mM} \mathrm{SDC}$
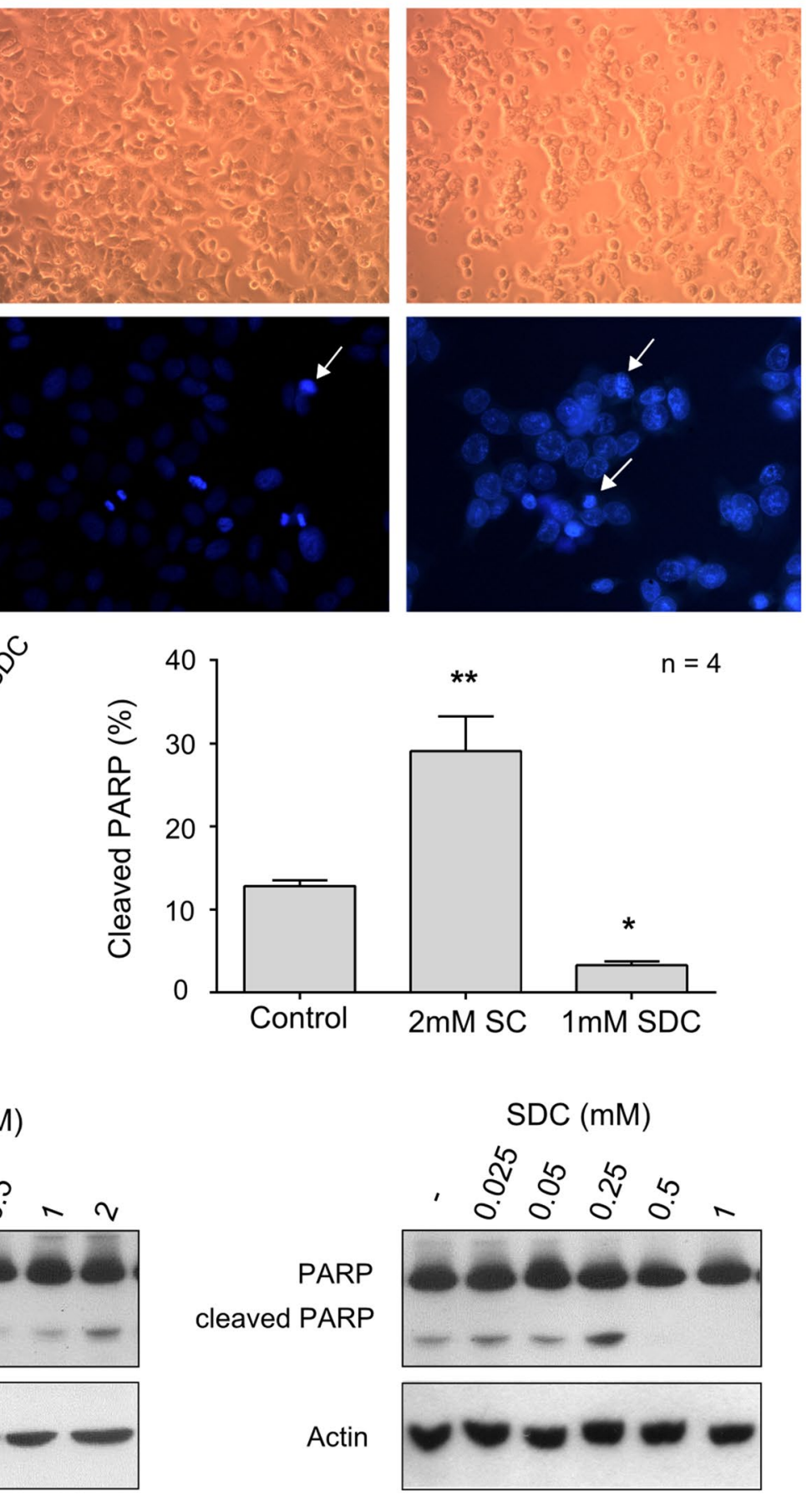

cleavage in cells treated with $2 \mathrm{mM}$ SC or $1 \mathrm{mM}$ SDC. c Representative Western blot showing PARP cleavage after BSs treatment with 0.05-2 mM SC or 0.025-1 mM SDC. Actin was used as loading control

chromatin condensation and fragmentation, while SDCtreated cells showed karyorrhexis and pyknotic nuclei (Fig. 4a). Increased levels of cleaved PARP were observed 
A

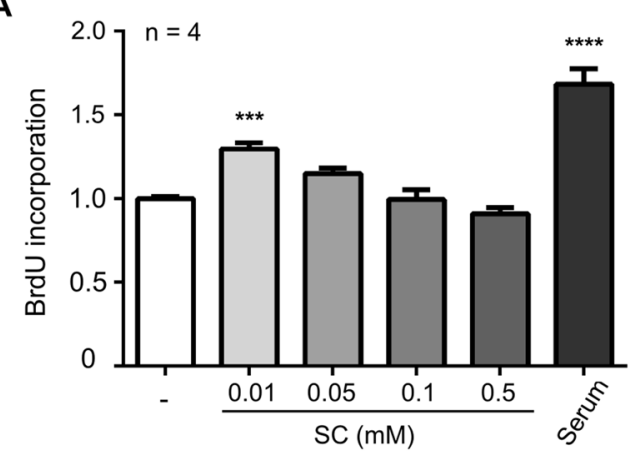

D
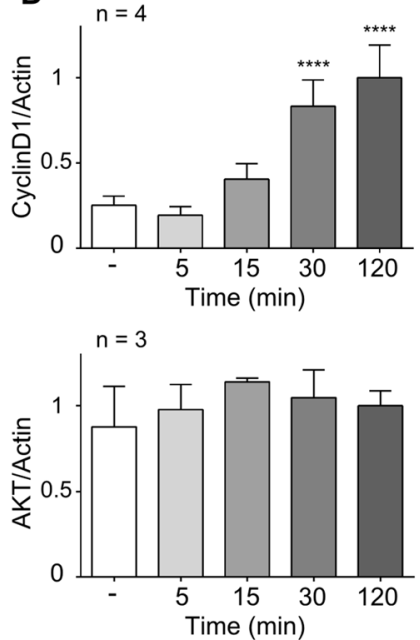

$\mathbf{F}$
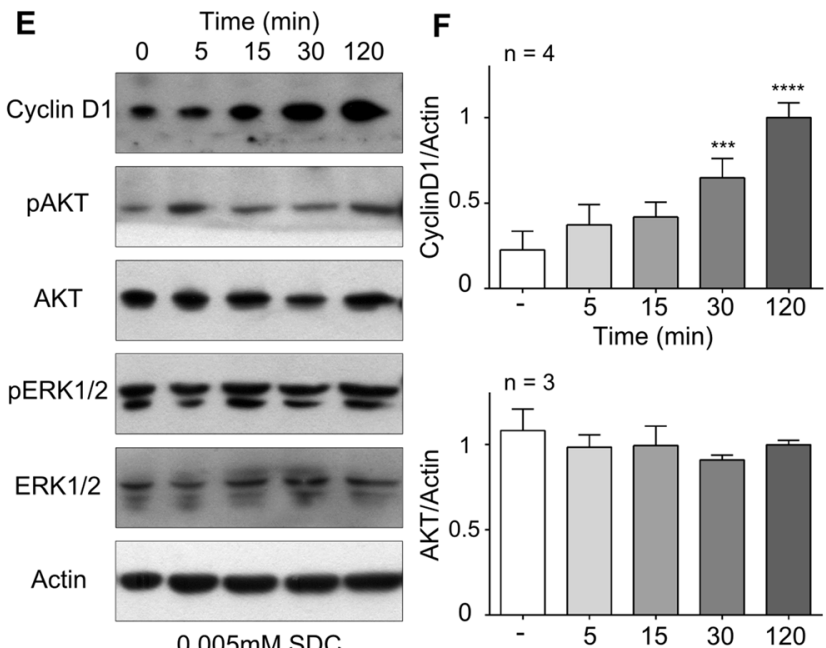

$0.005 \mathrm{mM}$ SDC

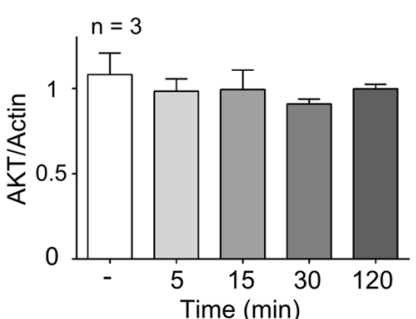

B

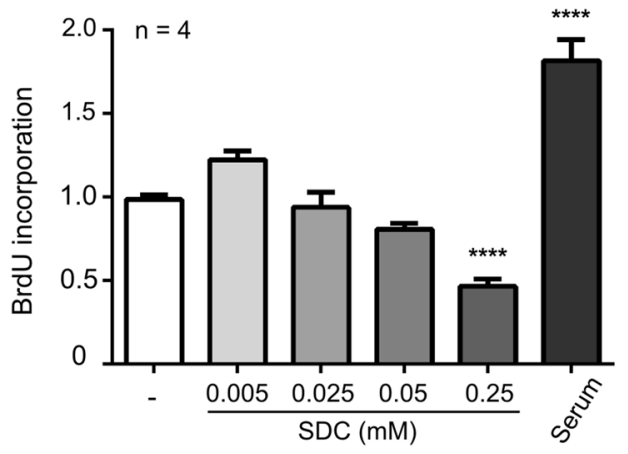

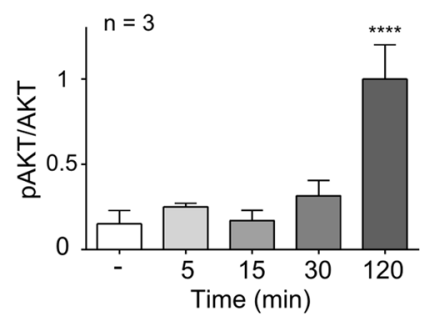
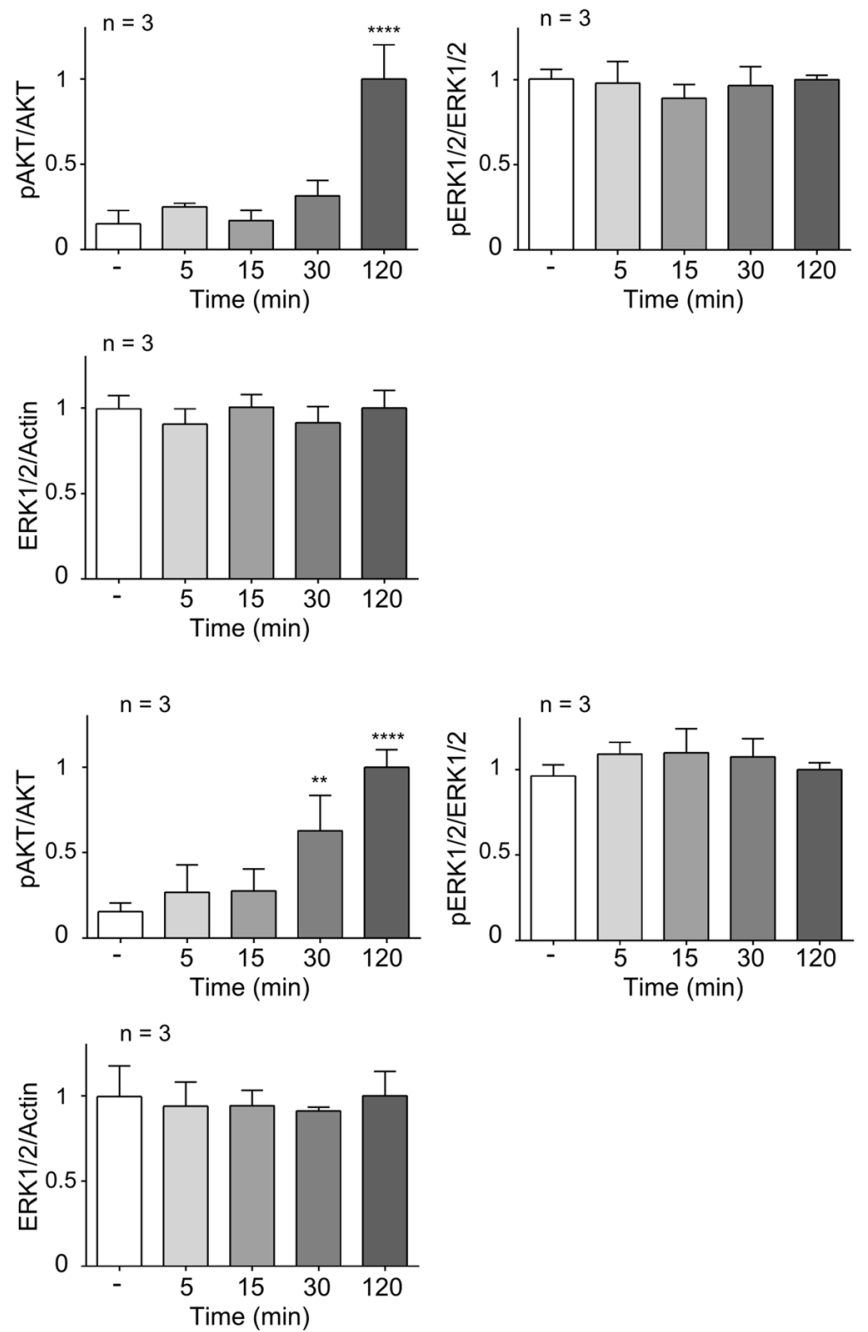

Fig. 5 BSs affect cell proliferation. MCF-7 cells were incubated in the presence of a $0.01-0.5 \mathrm{mM}$ SC or b $0.005-0.250 \mathrm{mM} \mathrm{SDC}$, and cell proliferation was determined from BrdU incorporation. Serum was used as positive control. Triplicates were run for each treatment. Values were relativized to the value recorded in control cells.

in cells exposed to SC, an effect that was not observed in SDC-treated cells at $24 \mathrm{~h}$ of incubation (Fig. 4b). However, PARP cleavage showed a dependence on BSs concentration

c, e Representative Western blots showing the activation of signaling kinases in cells exposed to $0.01 \mathrm{mM}$ SC or $0.05 \mathrm{mM}$ SDC. d, f Quantification of protein phosphorylation and total content, relativized to the value recorded at $2 \mathrm{~h}$ of incubation with the BSs

(Fig. 4c). This dependency was observed for SDC-treated cells only for the lower and intermediate concentrations assessed (Fig. 4c). 


\section{Effects of the BSs on cell proliferation and migration}

As mentioned before, and in opposition to what was observed in cells exposed to high concentrations of SC and SDC, low amounts of these BSs increased cell viability (Fig. 1). To further analyze if this effect was caused by the induction of cell proliferation, the incorporation of BrdU to newly synthesized DNA was quantified. Determinations were performed after $48 \mathrm{~h}$ of cell exposure to SC (0.01 to $0.5 \mathrm{mM})$ or SDC (0.005 to $0.25 \mathrm{mM})$. A small but significant increase in cell proliferation was observed only for cells incubated with $0.01 \mathrm{mM} \mathrm{SC}$ (Fig. 5a). A tendency towards higher BrdU incorporation $(\mathrm{p}=0.187)$ was described in cells incubated with the lowest concentration of SDC assessed (Fig. 5b). At higher SDC concentrations, BrdU incorporation was decreased in a concentration dependent manner, being the value measured at $0.25 \mathrm{mM}$ SDC $50 \%$ lower than in the controls (Fig. 5b). To investigate if, under the current conditions, the activation of the kinases involved in cell proliferation and survival was affected by the BSs, the levels of ERK1/2 and AKT phosphorylation were next analyzed. In addition, cyclin D1 expression was assessed as a marker of proliferating cells. Cells were incubated in the presence of either $0.01 \mathrm{mM} \mathrm{SC}$ or $0.005 \mathrm{mM} \mathrm{SDC}$ for 5, 15, 30 or $120 \mathrm{~min}$. Obtained results indicated a time-dependent effect on cyclin D1 expression and AKT phosphorylation (Fig. 5c-f). Cyclin D1 was significantly increased after 30 and 120 min of incubation for both BSs (Fig. 5c-f). SDC also had significant effects on pAKT at 30 and $120 \mathrm{~min}$ (Fig. 5e, f) whereas SC only increased AKT phosphorylation after 120 min of incubation (Fig. 5c, d). In contrast, no differences were observed in ERK1/2 phosphorylation levels throughout the period assessed (Fig. 5c-f).

Finally, we investigated the capacity of BSs to promote in vitro MCF-7 cell migration and wound healing. Experiments were performed using those concentrations of BSs that increased proliferation. Scratched cell monolayers were added with $0.010 \mathrm{mM} \mathrm{SC}$ or $0.005 \mathrm{mM}$ SDC in the absence of serum, and wound closure was studied by comparing the cell-free area at 24 and $48 \mathrm{~h}$ of incubation respect to the initial (T0) area of the scratch. Representative images obtained at T0, 24 and $48 \mathrm{~h}$ are shown in Fig. 6a. The quantification of remaining wound area showed no statistical differences among the treatments (Fig. 6b).

\section{Effects of the BSs on plasma membrane fluidity and hydration}

Since BSs can interact directly with the components of biological membranes and considering that it was demonstrated that clustering of membrane components could lead to unspecific activation of signaling pathways [40-42], we investigated if SC and/or SDC could affect the fluidity of MCF-7 cell plasma membrane.

First, we evaluated the fluidity of the membranes at three different depths of the bilayer. For that, after cell incubation for $24 \mathrm{~h}$ with either the minimal or maximal concentration of SC or SDC assessed in the previous experiments, cells were labeled with the fluorescent probes 6-AS (Fig. 7a), 12-AS (Fig. 7b) or 16-AP (Fig. 7c). The fluidity at the most superficial region of the membrane was affected by none of the BSs (Fig. 7a). In contrast, higher membrane fluidities at the intermediate depth of the bilayer were recorded in cells treated with SC or with the maximal concentration of SDC ( $\mathrm{P}<0.05$ vs. controls; Fig. $7 \mathrm{~b})$, as evidenced from the decrease in the fluorescence anisotropy of 12-AS. Only 2 mM SC caused significant ( $\mathrm{p}<0.05 v s$ controls) fluidification of the membrane at the deepest region $(\mathrm{p}<0.05 \mathrm{vs}$. controls; Fig. 7c).

Next, the impact of the BSs on the fluidity of the exofacial and cytosolic hemilayers of the plasma membrane was evaluated using the probes PA-DPH and TMA$\mathrm{DPH}$, respectively. As expected, SC and SDC increased the fluidity of the exofacial side of the membrane, an effect that was significant ( $\mathrm{p}<0.05 v s$. controls) only at the highest BS concentration assessed (Fig. 7d). A tendency towards higher fluidity of the cytosolic hemilayer was also observed (Fig. 7e). The hydration of the plasma membrane, which is determined by its fluidity, was evaluated with the fluorescent probe Laurdan. As shown in Fig. 7f, both SC and SDC caused significant $(\mathrm{P}<0.05$ $v s$. controls) decrease in the parameter GPexc, indicative of higher membrane hydration. This effect was observed even at the lowest BS concentration assessed.

Finally, the kinetics of the initial impact of the BSs on plasma membrane fluidity was evaluated using the probe PADPH. As shown in Fig. 8, the fluidity of the exofacial side of the bilayer of cells exposed to SC or SDC remained unaffected until at least $72 \mathrm{~min}$ of incubation. These results suggest that the early activation of signaling kinases described above, would not be triggered by BS-mediated promotion of alterations in plasma membrane biophysical properties that could affect intracellular cell signaling.

\section{Morphological characterization of the BSs}

Bile salts are able to spontaneously self-assemble to form aggregates with different shapes such as spherical micelles, planar bilayers, cylindrical micelles or vesicles. It has been established that a particle's shape and dimension influences interaction with cell membranes and uptake into cells [43, 44]. Considering the different effects observed for SC and SDC and their dependence on BS concentration, we next characterized the size and morphology of the structures 


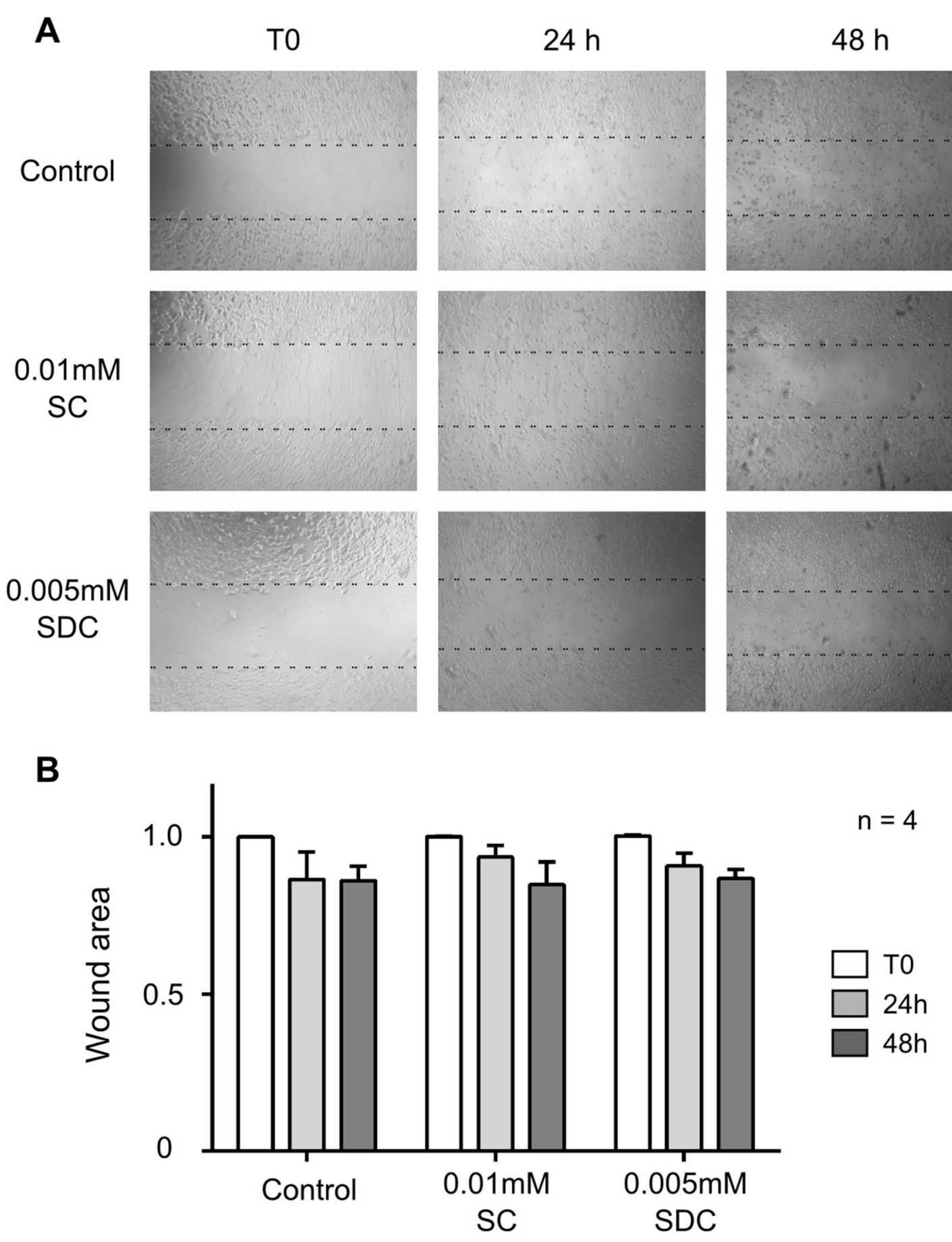

Fig. 6 BSs do not affect cell migration. MCF-7 cells were incubated for 24 or $48 \mathrm{~h}$ in the presence of $0.01 \mathrm{mM} \mathrm{SC}$ or $0.005 \mathrm{mM} \mathrm{SDC}$. Wound closure was studied by comparing the cell-free area respect to

formed, respectively, at the lowest and highest BSs concentrations investigated.

$\mathrm{SC}(0.010$ and $2 \mathrm{mM})$ and SDC $(0.005$ and $1 \mathrm{mM})$ were prepared in distilled water and the size of the particles was analyzed by dynamic light scattering (DLS). As shown in Table 1, a bimodal size distribution was observed for the BSs the initial (T0) area of the scratch. a Representative images obtained at T0, 24 and $48 \mathrm{~h}$. b Wounded area was measured and values were relativized to the initial area (T0) within each treatment

colloidal dispersions. On the one hand, the SC dispersions exhibited a higher size population of $\sim 287-362 \mathrm{~nm}$ and a lower size population of $\sim 38-63 \mathrm{~nm}$, regardless the concentration assayed (Table 1). Particularly, it was observed that the small size population increased its relative abundance as the BS concentration was increased from 0.010 to $2 \mathrm{mM}$. 
A

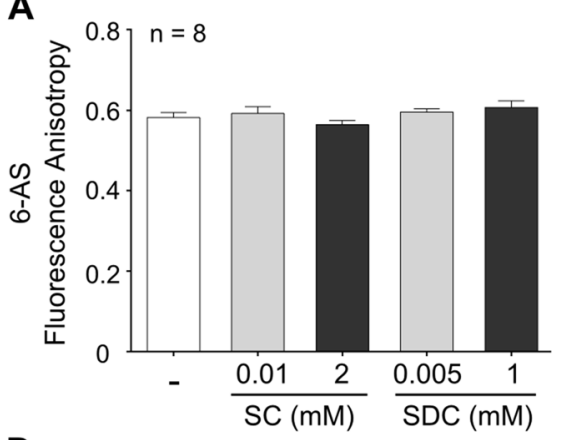

D

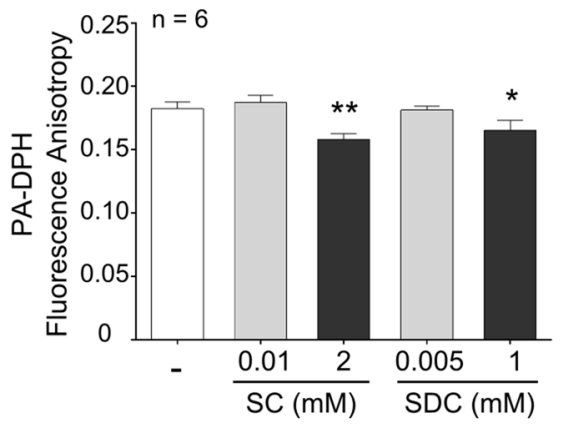

B

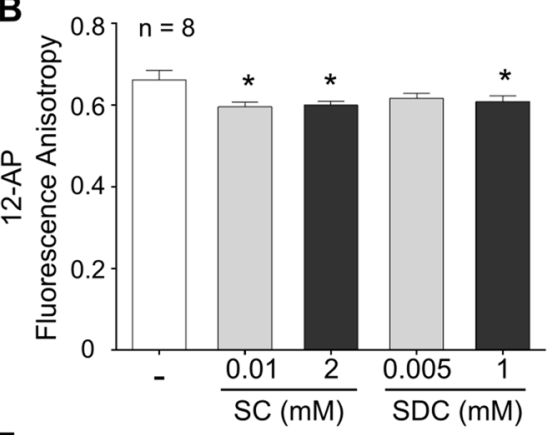

E

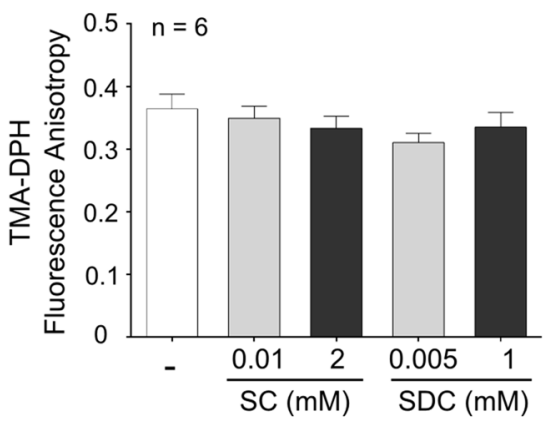

C

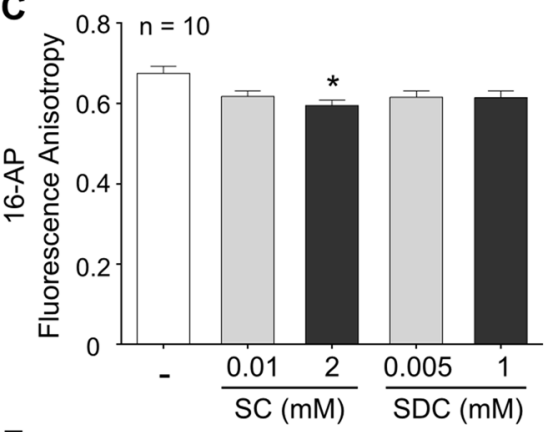

$\mathbf{F}$

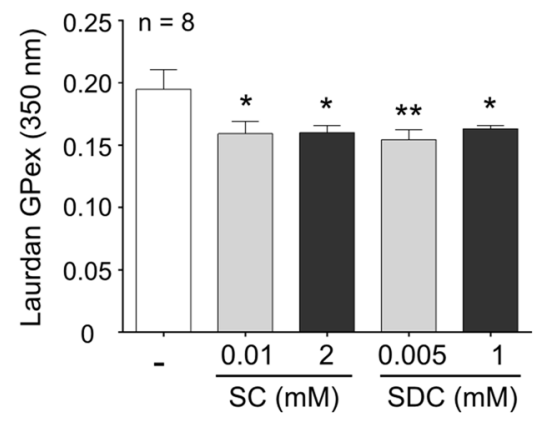

Fig. 7 BSs increase plasma membrane fluidity and hydration. MCF-7 cells were incubated for $24 \mathrm{~h}$ in the presence of SC or SDC. At the end of incubation, samples were labeled with the fluorescent probes a
6-AS, b 12-AP, c 16-AP, d PA-DPH, e TMA-DPH, or f Laurdan, and the a-e fluorescence anisotropy or $\mathbf{f}$ generalized polarization were recorded
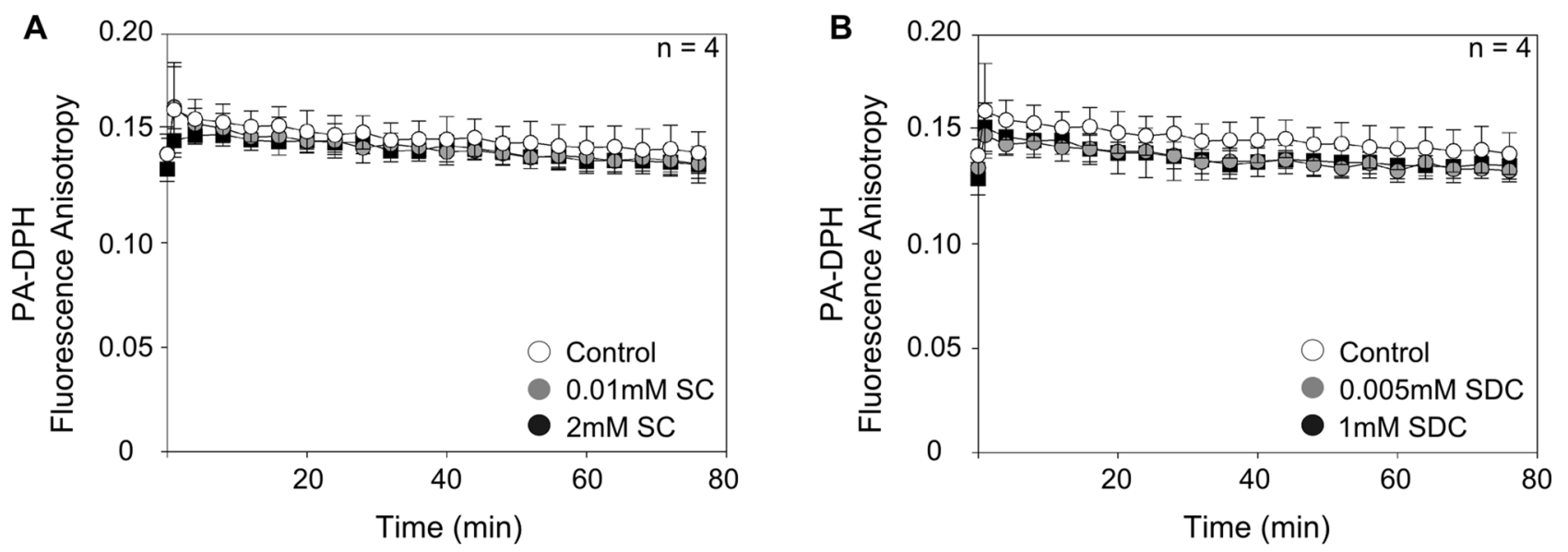

Fig. 8 Short-term cell exposure to BSs does not affect plasma membrane fluidity. MCF-7 cells were labeled with the fluorescent probe PA-DPH, added with $\mathbf{a}$ SC or $\mathbf{b}$ SDC, and the fluorescence anisotropy of the probe was recorded

On the other hand, $0.005 \mathrm{mM}$ SDC dispersions presented an unimodal size distribution with an average hydrodynamic diameter of $438.8 \pm 17.8 \mathrm{~nm}$. As the BS concentration was increased ( $1 \mathrm{mM})$, a bimodal size distribution was observed with size populations of $-75 \mathrm{~nm}$ and $364.8 \mathrm{~nm}$ (Table 1). At low BSs concentration, the size of the most abundant fraction in SDC solutions was significantly higher $(\mathrm{p}<0.05$, two-way ANOVA) than the corresponding SC solution, with no differences observed for the high BS concentration.
Finally, to gain further insight in the particle characterization of the SB dispersions, a morphological analysis was performed by means of transmission electron microscopy (TEM). As it could be seen in Fig. 9, the morphology of the SBs particles was spherical for both, SC and SDC dispersions. 
Table 1 BSs particle size characterization

\begin{tabular}{|c|c|c|c|c|c|c|}
\hline \multirow[t]{2}{*}{$\mathrm{n}=3$} & \multicolumn{3}{|l|}{ Peak 1} & \multicolumn{3}{|l|}{ Peak 2} \\
\hline & Size $(\mathrm{nm})$ & SD & Intensity (\%) & Size (nm) & SD & Intensity (\%) \\
\hline \multicolumn{7}{|l|}{$\mathrm{SC}$} \\
\hline $0.01 \mathrm{mM}$ & 38.2 & 4.3 & 11.8 & 287.4 & 50.6 & 88.2 \\
\hline $2 \mathrm{mM}$ & 63.1 & 0.5 & 45 & 362.1 & 58.5 & 55 \\
\hline \multicolumn{7}{|l|}{ SDC } \\
\hline $0.005 \mathrm{mM}$ & 438.8 & 17.8 & 89.8 & - & - & - \\
\hline $1 \mathrm{mM}$ & 75.2 & 17 & 12.6 & 364.8 & 35 & 87.4 \\
\hline
\end{tabular}

Peak analysis of the intensity and size distribution measured by Dynamic Light Scattering
A

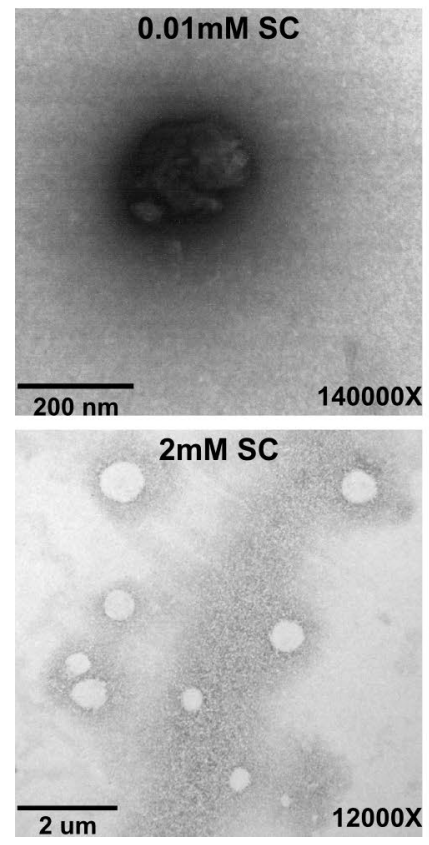

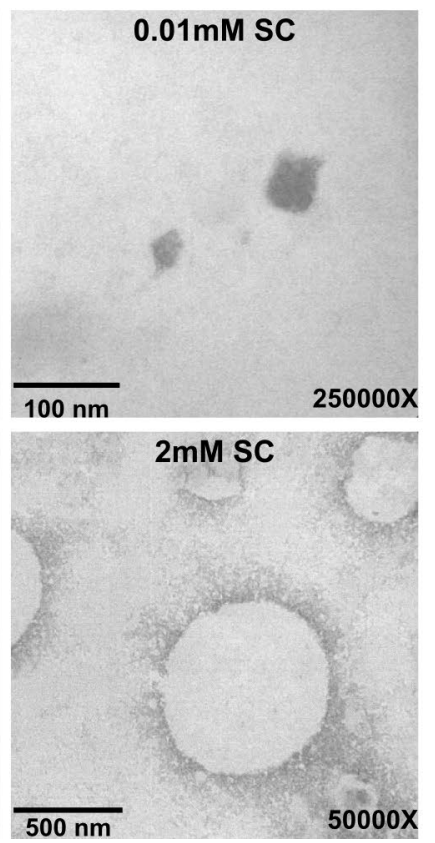

B

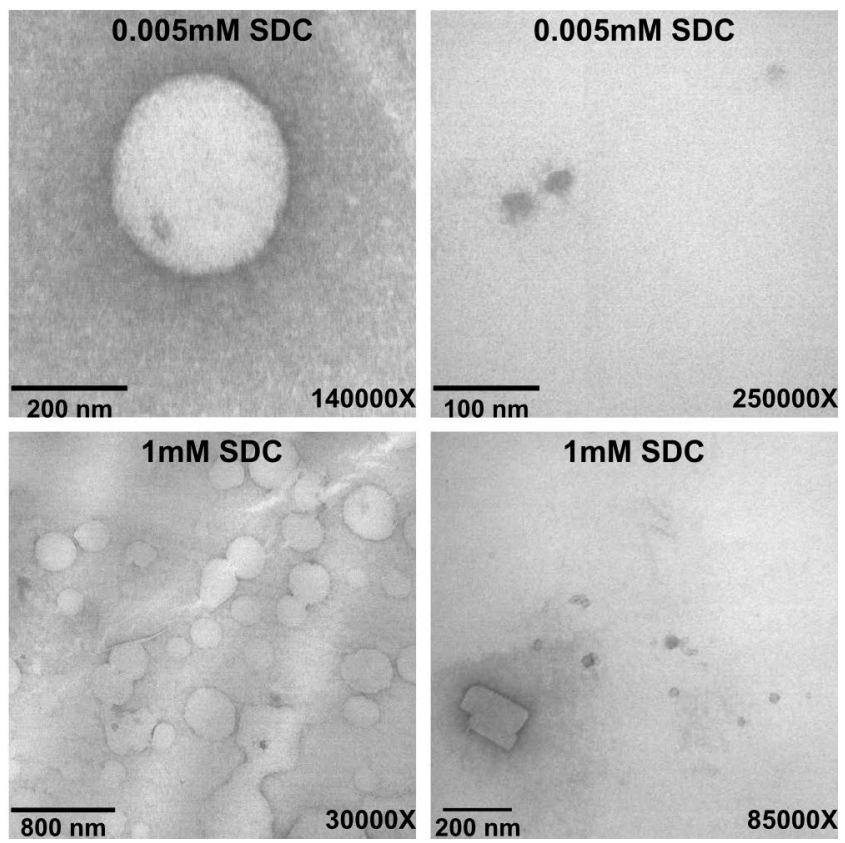

Fig. 9 BSs morphological characterization. Representative TEM images obtained for aqueous solutions of a $0.01 \mathrm{mM}$ (upper panel) and $2 \mathrm{mM}$ (lower panel) SC, and b $0.005 \mathrm{mM}$ (upper panel) and $1 \mathrm{mM}$ (lower panel) SDC

\section{Effects of BSs in the MDA-MB-231 cell line}

The more significant effects described for the BSs over the MCF-7 cells were confirmed in a second breast cancer cell line. For this purpose, the MDA-MB-231 cell line was chosen. While the MCF-7 cell line expresses the estrogen receptor (ER) and the progesterone receptor (PR), the MDAMB-231 are negative for these proteins [45]. Considering that mitogenic effects of BAs were associated to their estrogenic actions [45], activation of signaling pathways by SC and SDC were probed in a cell line that lacks ER expression.

First, the effects of the BSs on breast cancer cells viability were determined upon their incubation for $24 \mathrm{~h}$ (Suppl. Figure $1 \mathrm{a}$ and $\mathrm{b}$ ) or $48 \mathrm{~h}$ (Fig. 10a, b) with SC or SDC, covering the range of concentrations previously assayed
( 0.025 to $2 \mathrm{mM})$. In agreement with results obtained for the MCF-7 cell line, the viability and/or mitochondrial functionality of cells slightly increased when cells were incubated with SC 0.05 and $0.1 \mathrm{mM}$. On the other hand, significant cytotoxic effects were observed for the highest SC concentration assayed at $48 \mathrm{~h}$ (Fig. 10a). SDC also showed concentration dependent effects over MDA-MB-231 viability. Cell viability showed a modest increased for the lowest SDC concentrations assayed, but pronounced cytotoxic effects were induced when cells were incubated with SDC 0.5 and $1 \mathrm{mM}$ (Fig. 10b). Subsequently, the activation of Akt and p38 were analyzed after MDA-MB-231 cells exposure to SC $2 \mathrm{mM}$ or SDC $1 \mathrm{mM}$ during different time intervals (Fig. 10c-f). SC $2 \mathrm{mM}$ and SDC $1 \mathrm{mM}$ induced a significantly increase in AKT phosphorylation $2 \mathrm{~h}$ after stimulation as well as at the longer periods assessed (Fig. 10c, d). p38 was significantly 


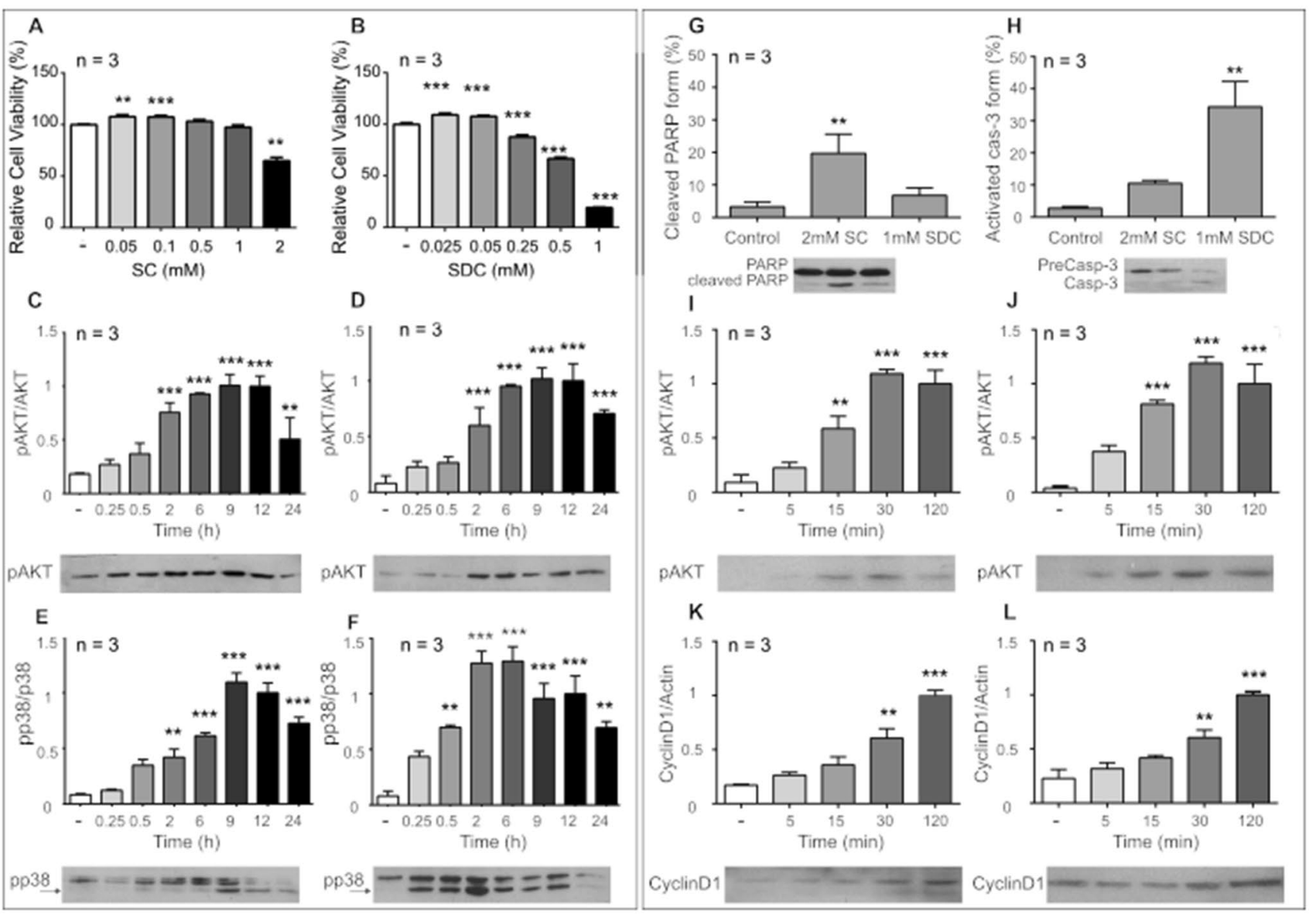

Fig. 10 BSs effects over MDA-MB-231 cells resemble those described in the MCF-7 cells. MDA-MB-231 cells were incubated for $48 \mathrm{~h}$ in the presence of a $0.05-2 \mathrm{mM} \mathrm{SC}$ or b $0.025-1 \mathrm{mM}$ SDC. After incubation, cell viability was evaluated, and results were expressed as the percentage of the value recorded in untreated control cells. Triplicates were run for each treatment. MDA-MB-231 cells were incubated with $2 \mathrm{mM} \mathrm{SC}$ or $1 \mathrm{mM}$ SDC for different time periods $(0-24 \mathrm{~h})$. The activation of Akt and p38 by $2 \mathrm{mM} \mathrm{SC}(\mathbf{c}, \mathbf{e})$ or $1 \mathrm{mM}$ SDC (d, f) were analyzed by immunoblotting as indicated in the legend to Fig. 2. Quantification of protein phosphorylation and total content, relativized to the value recorded at $12 \mathrm{~h}$ of incu-

induced by SC $2 \mathrm{mM}$ and SDC $1 \mathrm{mM} 30 \mathrm{~min}$ after stimulation and remained activated at longer periods (Fig. 10e, f). No differences in total AKT and p38 expression levels were observed throughout the period assessed (Suppl. Figure 1c, d).

Results from cell viability assays and kinases activation assessment resembled those observed for the MCF-7 cells. Therefore, BSs effects on apoptosis promotion were analyzed. For this purpose, PARP cleavage and caspase-3 activation were studied after cells incubation with SC $2 \mathrm{mM}$ or SDC $1 \mathrm{mM}$ for $24 \mathrm{~h}$ (Fig. 10g, h, Suppl. Figure 1e). Significant increased levels of cleaved PARP were observed in cells exposed to SC, while SDC treated cells evidenced an increase in caspase-3 activation (Fig. 10g, h). bation. Representative western blots are shown in supplementary Fig. 1. MDA-MB-231 cells were incubated for $24 \mathrm{~h}$ in the presence of $2 \mathrm{mM}$ SC or $1 \mathrm{mM}$ SDC and PARP or caspase- 3 cleavage analyzed by immunoblotting $(\mathbf{g}, \mathbf{h})$ Actin was used as loading control. Representative Western blots are shown in supplementary Fig. 1. MDAMB-231 cells were incubated in the presence of $\mathbf{i}, \mathbf{k} 0.01 \mathrm{mM} \mathrm{SC}$ or j, $\mathbf{l} 0.005 \mathrm{mM}$ SDC and Akt activation and cyclin D1 expression were determined by immunoblotting. Quantification of protein phosphorylation and total content, relativized to the value recorded at $2 \mathrm{~h}$ of incubation with the BSs. Representative Western blots are shown in supplementary Fig. 1

Finally, the effects of BSs on cell proliferation induction were investigated. For this purpose, MDA-MB-231 cells were treated with BSs low concentrations and survival signaling and cell cycle promotion were evaluated (Fig. 10i, j, k, 1, Suppl. Figure 1f, g). Results from phospho-AKT and cyclin D1 immunoblots evidenced BSs activation of the kinase (Fig. 10i, j) as well as the induction of the cell cycle promoter cyclin D1 (Fig. 10k, l) in this cell line. 


\section{Discussion}

BAs are synthesized in the liver from cholesterol, generating primary BAs, mainly CDCA and cholic acid. During fasting, bile is concentrated in the gall bladder, whereas upon food intake it is secreted into the small intestine. BAs are modified by intestinal bacteria into secondary BAs (lithocholic acid and deoxycholic acid). SC and SDC are the salts derived from the corresponding primary and secondary BAs. As mentioned in the introduction, due to their extraordinary emulsifying and solubilizing properties, they are broadly used as delivery systems for medicines and cosmetics as well [46, 47]. However, certain BAs can be cancer promoters and even carcinogens [17-19], especially in the human gastrointestinal tract $[17,18]$.

So far, published results regarding the effects of BAs on breast cancer cells are conflictive, because of the differences in the type of BA and/or the concentration investigated. Endogenous BAs can play a protective role in breast cancer development through their interaction with $\mathrm{FXR} \alpha$ [48]. Supporting that, CDCA inhibits MCF-7 cell growth [49]. However, its glycol-derivative (glycol-CDCA) has the opposite effect, inducing cell proliferation [49]. In turn $10 \mu \mathrm{M}$ SDC was described to enhance survival and migration of human breast cancer MDA-MB-231 cells [50, 51]. This anti-apoptotic and chemokinetic effect did not agree with other studies that described that SDC induced apoptosis in cancer cells $[52,53]$. However, that pro-apoptotic effect relied on incubation with up to 50-fold higher concentrations of SDC. The molecular mechanisms underlying BA/ BS effects on mammary tissue are not completely elucidated, and the investigations carried out until now were restricted to those involving the activation of nuclear receptors, such as FXR $\alpha$, pregnane (PRX) and vitamin D (VDR) receptors [50, 54-57]. However, these compounds may also activate other families of receptors, including $\mathrm{G}$ protein-coupled receptors and those with intrinsic kinase activity.

The aim of the present work was to analyze the cellular response in breast cancer cells to two natural BSs, and the possible participation of signaling kinases as mediators. For this purpose, the response of MCF-7 cells to SC and SDC exposure was evaluated in terms of alterations in their viability, proliferation and migration capacities, and apoptosis promotion, and the most significant results were corroborated in a second breast cancer cells line, the MDA-MB-231. Experiments were performed in the absence of serum in the culture media to avoid the binding of these amphipathic molecules to serum proteins and/or lipoproteins [58], hence maximizing the probability of a direct interaction between the BSs and cells.

Cell viability was determined for a broad range of BSs concentrations that emulate either physiological or pathological contexts. Obtained results indicate that the BSs promoted different effects, depending both on their chemical structure and concentration. Overall, SC and SDC was biphasic since they maintained or slightly increased cell viability and/or mitochondrial functionality at low concentrations and decreased it at the higher ones.

The pattern of activation of key signaling kinases was characterized in the current experimental model to elucidate if the biological effects of BSs on MCF-7 cells could be related to the activation of signaling kinases. For this purpose, the phosphorylation of AKT, ERK1/2 and p 38 was analyzed upon cell incubation with different concentrations of SC or SDC during $24 \mathrm{~h}$. Subsequently, phosphorylation of the signaling mediators was studied after treatment with high concentrations of the BSs during different time intervals. Phosphorylation of these signaling kinases by bile acids has been previously described in cell types different from epithelial breast cells $[2,59,60]$. However, to the best of our knowledge, activation of these kinases has not been linked to bile acids mechanism of action in breast cancer cells, before. The molecular mechanisms underlying BAs effects were mainly associated to the activation of nuclear receptors, such as FXR $\alpha$, pregnane (PRX) and vitamin D (VDR) receptors in breast cancer cells. This is the first report showing that high BSs concentrations induce ERK1/2, AKT and p38 activation in MCF-7 cells. While the activation of ERK1/2 was transient and returned to control values between 6 and $9 \mathrm{~h}$ of incubation, the activation of AKT and p38 appeared more belatedly and persisted at least until $24 \mathrm{~h}$ of incubation.

At high concentrations, BSs were cytotoxic, and this effect could be associated with the sustained activation of AKT, which is a stressful stimulus that would lead to p38 activation. Alternatively, BSs can activate p38 via the generation of ROS and/or RNS that could also induce DNA oxidative damage [61, 62]. Supporting that, high levels of BSs induce apoptosis in colonic epithelial cells [17, 18], being DNA damage an initiating event of this process [63]. Interestingly, the BSs investigated in this study showed different effects on PARP cleavage, an enzyme responsible for DNA repair. PARP cleavage and apoptosis would be induced by both bile salts; however, the observed effects depend on the incubation time and bile salts concentration. Sodium deoxycholate induced apoptosis at lower concentrations than sodium cholate. When PARP cleavage was assayed $24 \mathrm{~h}$ after incubation with high bile salts concentrations, it was evidenced only in those samples incubated with SC but not in cells treated with SDC. However, PARP cleavage could be demonstrated for SDC lower concentrations. Exposure to cytotoxic concentrations of BAs would allow selectively the growth — and thus, population enrichment — of cells resistant to BA-induced apoptosis $[17,18]$. The molecular mechanisms underlying this process might rely on the simultaneous 
induction of apoptosis and the activation of AKT and survival pathways. Indeed, BAs have been described to induce survival mechanisms concomitantly with apoptotic pathways in hepatocytes and in colon epithelial cells [64]. Evidence of concomitant induction of survival and apoptotic mechanisms would rely on AKT and p38 activation, respectively, by high BSs concentrations. The balance between these pathways might determine the outcome-survival or death-of the transformed cells.

BSs can also favor cell proliferation, as suggested by the transient activation of ERK1/2. On this basis, and considering the increased viability observed in cells exposed to low BS concentrations, their effects on cell proliferation and kinases activation were subsequently investigated. BrdU incorporation was increased in cells exposed to low concentrations of the BSs, an effect that agreed with the higher cyclin D1 expression and AKT activation found $2 \mathrm{~h}$ after cell stimulation. Therefore, we could hypothesize that in the current experimental model, the balance between survival and apoptotic signaling pathways might be in favor of cell survival and proliferation when cells are exposed to the lowest concentrations of BSs, while apoptosis and transformation might be the predominant events when cells are exposed to the highest BSs concentrations. The extent of AKT activation induced by BSs might have a defining role in the balance between survival and apoptosis. Persistent AKT activation by high BSs concentrations might have detrimental consequences on cells biology, while transient activation of AKT, induced by low BSs levels, would induce cell survival.

Although both BSs activated the same signaling pathways in MCF-7 cells, SDC affected cell proliferation at lower concentrations and seemed to be more cytotoxic than $\mathrm{SC}$, in accordance with previous reports that demonstrated its potent cytotoxic activity [39]. SDC also increased more pronouncedly the phosphorylation levels of $\mathrm{p} 38$ and AKT at lower concentrations. The subtle differences between SC and SDC molecular structures (Suppl. Figure 2) may affect differently the properties of cell plasma membrane, or the affinity and/or specificity for the interaction with their cognate receptors in mammary cells. The comparative analysis of SC and SDC chemical properties indicates that the latter has a lower polar surface and a higher tendency to incorporate into lipid bilayers. However, both SC and SDC can accommodate between plasma membrane lipids, potentially affecting their biophysical properties. For example, SDC promotes rapid redistribution of cholesterol in human colon adenocarcinoma (HCT116) cells, caveolae disruption, mild alteration in membrane fluidity, and the activation of EGFR and ERK1/2 [41]. In another model of adenocarcinoma cells (Caco- 2 cell line), 30 min-exposure to SDC altered the distribution of cholesterol but without affecting the fluidity of the plasma membrane, promoted the activation of the kinases ERK1/2, AKT and p38, the activation of the transcription factor AP-1, and induced cell apoptosis $[65,66]$. In the current work, we analyzed the impact of long term $(24 \mathrm{~h})$ cell exposure to SC and SDC on the fluidity of MCF-7 plasma membrane. Experiments were performed using the probes 6-AS, 12-AS and 16-AP, which have their fluorophores located approximately at 14, 19 and $21 \AA$ from membrane surface, respectively [67]. SC and SDC did not affect the fluidity at the most superficial level of the membrane. Instead, they increased the fluidity and hydration at the intermediate level of the bilayer, a region enriched in fatty acid unsaturations. The fluidifying effect of SC propagated deeper into the bilayer, as evidenced with 16-AP. To analyze which hemilayer of the plasma membrane was affected the most by the BSs, cells were labeled with the probes PA-DPH or TMA-DPH that sense changes in the fluidity of the exofacial and cytosolic leaflets of the plasma membrane, respectively [35]. The finding that only the exofacial side of the membrane was affected by SC and SDC is compatible with the notion that, once incorporated into the membrane, the negative charge of their carboxyl groups restricts the capacity of these compounds to undergo transbilayer (flip-flop) motion. Accordingly, the half-time (t1/2) calculated for SC and SDC flip-flop in model membranes increased from milliseconds for the non-charged species, to more than $24 \mathrm{~h}$ for the charged ones [68], supporting the hypothesis that the earliest biological effects of these compounds should be triggered at the plasma membrane level. However, the fluidifying effects of SC and SDC in this cell model are not rapid, as evidenced from the kinetic analysis of PA-DPH anisotropy during the first $80 \mathrm{~min}$ of cell exposure to the compounds.

Being amphiphilic molecules, BSs form self-assembled micellar structures in aqueous solutions, which vary in size and morphology depending both on the BSs used and their concentration [69]. Therefore, the kind of interactions that BSs will establish with the cells, as well as their biological effects, will be partially determined by those structures. To further understand the relationship between the morphology of BSs micelles and their interaction with membranes, and ultimately their effects in breast cancer cells, SC and SDC solutions were analyzed by DLS and TEM. The SC and SDC solutions used in this work showed different patterns of size distribution depending on BS concentration. While the increase in $\mathrm{SC}$ concentration was accompanied by a moderate increase in the size of the particles, the increase in SDC concentration slightly reduced it. The most abundant subpopulation of particles had an intermediate size (300-400 nm), being the particles generated at low SDC concentration 52\% higher than those of SC. Despite of this, and given the similarities observed between the effects caused by SC and SDC at low concentration, it is possible to conclude that they cannot be strictly associated with differences in the morphology of the particles. Instead, they could be due to differences in the nature and/or strength of 
the interactions that these compounds may establish with membrane components.

The concentration dependent effects of BSs over breast cancer cell lines and activation of signaling kinases were confirmed in a second cell line substantially different from the MCF-7. For this purpose, the MDA-MB-231 cells were used. While the MCF-7 cell line expresses the ER and PR and shows HER2 amplification, those molecular characteristics are not present in the MDA-MB-231 cells, which are considered a model of the triple negative breast cancer. Although their significant molecular differences, both cell lines responded similarly to the bile salts. Viability of MDAMB-231 cells showed a concentration dependent response to BSs. Low BSs concentrations induced a modest increased in cell viability, transient AKT activation and induction of cyclin D1 expression, while high BSs concentrations triggered an important decreased in cell viability, apoptosis and sustained activation of AKT and p38.

\section{Conclusions}

Bile acids are important signaling molecules with multiple physiological and pathophysiological actions. Their effects would vary depending on their chemical structure, physicochemical properties, as well as on the receptors and signaling pathways triggered, or tissue considered. This investigation constitutes a first approach in the study of the mechanisms by which BSs induce kinase mediated cell signaling pathways in breast cancer cells.

Author contributions YG, LG: conceived or designed study, YG, MB, CF, MB, TL, SV, LG: performed research, YG, CF, MM, DC, SV, LG: analyzed data, MM, DC, SV: contributed with new methods or models, YG, SV, LG: wrote the paper. All authors have read and approved the manuscript.

Funding MM, DC, SV and LG are Career Investigators of CONICET. $\mathrm{CF}$ is supported by a fellowship from the National Interuniversity Council (CIN) and MB and TL are supported by a fellowship from the University of Buenos Aires. Support for these studies was provided by CONICET (PIP-320) and ANPCYT (PICT 2013-937) to LG, and by UBA 20020130200005BA to LG and 20020130100195BA to SV. The funding sources had no involvement in the conduct of the research and/ or preparation of the article.

Data Availability All data generated or analyzed during this study are included in this published article [and its supplementary information files].

\section{Compliance with ethical standards}

Conflict of interest The authors declare that they have no conflict of interest.

\section{References}

1. Hofmann AF, Hagey LR (2008) Bile acids: chemistry, pathochemistry, biology, pathobiology, and therapeutics. Cell Mol Life Sci 65(16):2461-2483. https://doi.org/10.1007/s00018-008-7568-6

2. Copple BL, Li T (2016) Pharmacology of bile acid receptors: Evolution of bile acids from simple detergents to complex signaling molecules. Pharmacol Res 104:9-21. https://doi.org/10.1016/j. phrs.2015.12.007

3. Sarenac TMMM (2018) Bile acid synthesis: from nature to the chemical modification and synthesis and their applications as drugs and nutrients. Front Pharmacol 9: https://doi.org/10.3389/ fphar.2018.00939

4. Mace TA, Shakya R, Elnaggar O, Wilson K, Komar HM, Yang J, Pitarresi JR, Young GS, Ostrowski MC, Ludwig T, Bekaii-Saab T, Bloomston M, Lesinski GB (2015) Single agent BMS-911543 Jak2 inhibitor has distinct inhibitory effects on STAT5 signaling in genetically engineered mice with pancreatic cancer. Oncotarget 6(42):44509-44522. https://doi.org/10.18632/oncotarget.6332

5. Faustino C, Serafim C, Rijo P, Reis CP (2016) Bile acids and bile acid derivatives: use in drug delivery systems and as therapeutic agents. Expert Opin Drug Deliv 13(8):1133-1148. https://doi. org/10.1080/17425247.2016.1178233

6. Selvam S, Andrews ME, Mishra AK (2009) A photophysical study on the role of bile salt hydrophobicity in solubilizing amphotericin B aggregates. J Pharm Sci 98(11):4153-4160. https://doi. org/10.1002/jps.21718

7. Atanackovic M, Posa M, Heinle H, Gojkovic-Bukarica L, Cvejic J (2009) Solubilization of resveratrol in micellar solutions of different bile acids. Colloids Surf B Biointerfaces 72(1):148-154. https://doi.org/10.1016/j.colsurfb.2009.03.029

8. Moghimipour E, Ameri A, Handali S (2015) Absorption-Enhancing Effects of Bile Salts. Molecules 20(8):14451-14473. https:// doi.org/10.3390/molecules200814451

9. Reis CP, Silva C, Martinho N, Rosado C (2013) Drug carriers for oral delivery of peptides and proteins: accomplishments and future perspectives. Ther Deliv 4(2):251-265. https://doi. org/10.4155/tde. 12.143

10. Aburahma MH (2016) Bile salts-containing vesicles: promising pharmaceutical carriers for oral delivery of poorly water-soluble drugs and peptide/protein-based therapeutics or vaccines. Drug Deliv 23(6):1847-1867. https://doi.org/10.3109/10717 544.2014.976892

11. Tang X, Cai S, Zhang R, Liu P, Chen H, Zheng Y, Sun L (2013) Paclitaxel-loaded nanoparticles of star-shaped cholic acid-core PLA-TPGS copolymer for breast cancer treatment. Nanoscale Res Lett 8(1):420. https://doi.org/10.1186/1556-276X-8-420

12. Chaturvedi K, Ganguly K, Kulkarni AR, Rudzinski WE, Krauss L, Nadagouda MN, Aminabhavi TM (2015) Oral insulin delivery using deoxycholic acid conjugated PEGylated polyhydroxybutyrate co-polymeric nanoparticles. Nanomedicine (Lond) 10(10):1569-1583. https://doi.org/10.2217/nnm.15.36

13. Zengin A, Yildirim E, Tamer U, Caykara T (2013) Molecularly imprinted superparamagnetic iron oxide nanoparticles for rapid enrichment and separation of cholesterol. Analyst 138(23):7238 7245. https://doi.org/10.1039/c3an01458d

14. Cook JW KE, Kennaway NM (1940) Production of tumours in mice by deoxycholic acid. Nature 145 (627)

15. Narisawa T, Magadia NE, Weisburger JH, Wynder EL (1974) Promoting effect of bile acids on colon carcinogenesis after intrarectal instillation of $\mathrm{N}$-methyl-N'-nitro-N-nitrosoguanidine in rats. J Natl Cancer Inst 53(4):1093-1097

16. Kobori O, Watanabe J, Shimizu T, Shoji M, Morioka Y (1984) Enhancing effect of sodium taurocholate on 
N-methyl-N'-nitro-N-nitrosoguanidine-induced stomach tumorigenesis in rats. Gan 75(8):651-654

17. Bernstein NK, Williams RS, Rakovszky ML, Cui D, Green R, Karimi-Busheri F, Mani RS, Galicia S, Koch CA, Cass CE, Durocher D, Weinfeld M, Glover JN (2005) The molecular architecture of the mammalian DNA repair enzyme, polynucleotide kinase. Mol Cell 17(5):657-670. https://doi.org/10.1016/j.molce 1.2005.02.012

18. Bernstein H, Bernstein C, Payne CM, Dvorak K (2009) Bile acids as endogenous etiologic agents in gastrointestinal cancer. World $\mathrm{J}$ Gastroenterol 15(27):3329-3340

19. Costarelli V (2009) Bile acids as possible human carcinogens: new tricks from an old dog. Int J Food Sci Nutr 60(Suppl 6):116-125. https://doi.org/10.1080/09637480902970967

20. DeRubertis FR, Craven PA, Saito R (1984) Bile salt stimulation of colonic epithelial proliferation: evidence for involvement of lipoxygenase products. J Clin Invest 74(5):1614-1624. https://doi. org/10.1172/JCI111577

21. Craven PA, Pfanstiel J, DeRubertis FR (1986) Role of reactive oxygen in bile salt stimulation of colonic epithelial proliferation. J Clin Invest 77(3):850-859. https://doi.org/10.1172/JCI112382

22. Dent P, Fang Y, Gupta S, Studer E, Mitchell C, Spiegel S, Hylemon PB (2005) Conjugated bile acids promote ERK1/2 and AKT activation via a pertussis toxin-sensitive mechanism in murine and human hepatocytes. Hepatology 42(6):1291-1299. https:// doi.org/10.1002/hep.20942

23. Studer FR, Gratz KW, Mutzbauer TS (2012) Comparison of clonidine and midazolam as anxiolytic premedication before wisdom tooth surgery: a randomized, double-blind, crossover pilot study. Oral Maxillofac Surg 16(4):341-347. https://doi.org/10.1007/ s10006-012-0319-8

24. Drasar BS, Irving D (1973) Environmental factors and cancer of the colon and breast. Br J Cancer 27(2):167-172

25. van Faassen A, Ochsenkuhn T, Houterman S, van der Ploeg EM, Bueno-de-Mesquita BH, Ocke MC, Bayerdorffer E, Janknegt RA (1997) Plasma deoxycholic acid is related to deoxycholic acid in faecal water. Cancer Lett 114(1-2):293-294. https://doi. org/10.1016/s0304-3835(97)04683-1

26. Blazquez AMG, Macias RIR, Cives-Losada C, de la Iglesia A, Marin JJG, Monte MJ (2017) Lactation during cholestasis: Role of $\mathrm{ABC}$ proteins in bile acid traffic across the mammary gland. Sci Rep 7(1):7475. https://doi.org/10.1038/s41598-017-06315-8

27. Gudmundsson S, Moller TR, Olsson H (1989) Cancer incidence after cholecystectomy-a cohort study with 30 years follow-up. Eur J Surg Oncol 15(2):113-117

28. Baker PR, Reid, A.D., Siow, Y., \& Preece, P.E. (1986) Bile acids in human breast cyst fluid BiochemSocTrans 14 (962)

29. Raju U, Levitz M, Javitt NB (1990) Bile acids in human breast cyst fluid: the identification of lithocholic acid. J Clin Endocrinol Metab 70(4):1030-1034. https://doi.org/10.1210/jcem-70-4-1030

30. Journe F, Laurent G, Chaboteaux C, Nonclercq D, Durbecq V, Larsimont D, Body JJ (2008) Farnesol, a mevalonate pathway intermediate, stimulates MCF-7 breast cancer cell growth through farnesoid-X-receptor-mediated estrogen receptor activation. Breast Cancer Res Treat 107(1):49-61. https://doi.org/10.1007/ s10549-007-9535-6

31. Baptissart M, Vega A, Maqdasy S, Caira F, Baron S, Lobaccaro JM, Volle DH (2013) Bile acids: from digestion to cancers. Biochimie 95(3):504-517. https://doi.org/10.1016/j.bioch i.2012.06.022

32. Gonzalez L, Diaz ME, Miquet JG, Sotelo AI, Fernandez D, Dominici FP, Bartke A, Turyn D (2010) GH modulates hepatic epidermal growth factor signaling in the mouse. J Endocrinol 204(3):299-309. https://doi.org/10.1677/JOE-09-0372
33. Schneider CA, Rasband WS, Eliceiri KW (2012) NIH Image to ImageJ: 25 years of image analysis. Nat Methods 9(7):671-675

34. Celiz G, Alfaro FF, Cappellini C, Daz M, Verstraeten SV (2013) Prunin- and hesperetin glucoside-alkyl (C4-C18) esters interaction with Jurkat cells plasma membrane: consequences on membrane physical properties and antioxidant capacity. Food Chem Toxicol 55:411-423. https://doi.org/10.1016/j.fct.2013.01.011

35. Buffone MG, Doncel GF, Calamera JC, Verstraeten SV (2009) Capacitation-associated changes in membrane fluidity in asthenozoospermic human spermatozoa. Int J Androl 32(4):360-375. https://doi.org/10.1111/j.1365-2605.2008.00874.x

36. Verstraeten SV, Oteiza PI (2000) Effects of $\mathrm{Al}(3+)$ and related metals on membrane phase state and hydration: correlation with lipid oxidation. Arch Biochem Biophys 375(2):340-346. https:// doi.org/10.1006/abbi.1999.1671

37. Raju GC (1990) The histological and immunohistochemical evidence of squamous metaplasia from the myoepithelial cells in the breast. Histopathology 17(3):272-275

38. Costarelli V, Sanders TA (2002) Plasma deoxycholic acid concentration is elevated in postmenopausal women with newly diagnosed breast cancer. Eur J Clin Nutr 56(9):925-927. https://doi. org/10.1038/sj.ejcn.1601396

39. Tang W, Putluri V, Ambati CR, Dorsey TH, Putluri N, Ambs S (2019) Liver- and microbiome-derived bile acids accumulate in human breast tumors and inhibit growth and improve patient survival. Clin Cancer Res 25(19):5972-5983. https://doi. org/10.1158/1078-0432.CCR-19-0094

40. Qiao L, Studer E, Leach K, McKinstry R, Gupta S, Decker R, Kukreja R, Valerie K, Nagarkatti P, El Deiry W, Molkentin J, Schmidt-Ullrich R, Fisher PB, Grant S, Hylemon PB, Dent P (2001) Deoxycholic acid (DCA) causes ligand-independent activation of epidermal growth factor receptor (EGFR) and FAS receptor in primary hepatocytes: inhibition of EGFR/mitogenactivated protein kinase-signaling module enhances DCAinduced apoptosis. Mol Biol Cell 12(9):2629-2645. https://doi. org/10.1091/mbc.12.9.2629

41. Jean-Louis S, Akare S, Ali MA, Mash EA Jr, Meuillet E, Martinez JD (2006) Deoxycholic acid induces intracellular signaling through membrane perturbations. J Biol Chem 281(21):1494814960. https://doi.org/10.1074/jbc.M506710200

42. Liang H, Estes MK, Zhang H, Du G, Zhou Y (2018) Bile acids target proteolipid nano-assemblies of EGFR and phosphatidic acid in the plasma membrane for stimulation of MAPK signaling. PLoS ONE 13(8):e0198983. https://doi.org/10.1371/journal.pone.01989 83

43. Gratton SE, Ropp PA, Pohlhaus PD, Luft JC, Madden VJ, Napier ME, DeSimone JM (2008) The effect of particle design on cellular internalization pathways. Proc Natl Acad Sci USA 105(33):11613-11618. https://doi.org/10.1073/pnas.0801763105

44. Zhao Z, Ukidve A, Krishnan V, Mitragotri S (2019) Effect of physicochemical and surface properties on in vivo fate of drug nanocarriers. Adv Drug Deliv Rev 143:3-21. https://doi. org/10.1016/j.addr.2019.01.002

45. Subik K, Lee JF, Baxter L, Strzepek T, Costello D, Crowley P, Xing L, Hung MC, Bonfiglio T, Hicks DG, Tang P (2010) The expression patterns of er, pr, her2, ck5/6, egfr, ki-67 and ar by immunohistochemical analysis in breast cancer cell lines. Breast Cancer 4:35-41

46. Maldonado-Valderrama J, Wilde P, Macierzanka A, Mackie A (2011) The role of bile salts in digestion. Adv Colloid Interface Sci 165(1):36-46. https://doi.org/10.1016/j.cis.2010.12.002

47. Enhsen A KW, Wess G (1998) Bile acids in drug discovery. Drug Discov Today 3

48. Swales KE, Korbonits M, Carpenter R, Walsh DT, Warner TD, Bishop-Bailey D (2006) The farnesoid X receptor is expressed in 
breast cancer and regulates apoptosis and aromatase expression. Cancer Res 66(20):10120-10126. https://doi.org/10.1158/00085472.CAN-06-2399

49. Baker PR, Wilton JC, Jones CE, Stenzel DJ, Watson N, Smith GJ (1992) Bile acids influence the growth, oestrogen receptor and oestrogen-regulated proteins of MCF-7 human breast cancer cells. Br J Cancer 65(4):566-572

50. Silva J, Dasgupta S, Wang G, Krishnamurthy K, Ritter E, Bieberich $\mathrm{E}$ (2006) Lipids isolated from bone induce the migration of human breast cancer cells. J Lipid Res 47(4):724-733. https:// doi.org/10.1194/jlr.M500473-JLR200

51. Krishnamurthy K, Wang G, Rokhfeld D, Bieberich E (2008) Deoxycholate promotes survival of breast cancer cells by reducing the level of pro-apoptotic ceramide. Breast Cancer Res 10(6):R106. https://doi.org/10.1186/bcr2211

52. Zhang R, Gong J, Wang H, Wang L (2005) Bile salts inhibit growth and induce apoptosis of culture human normal esophageal mucosal epithelial cells. World J Gastroenterol 11(41):6466-6471. https://doi.org/10.3748/wjg.v11.i41.6466

53. Yui S, Kanamoto R, Saeki T (2008) Deoxycholic acid can induce apoptosis in the human colon cancer cell line HCT116 in the absence of Bax. Nutr Cancer 60(1):91-96. https://doi. org/10.1080/01635580701525893

54. Alasmael N, Mohan R, Meira LB, Swales KE, Plant NJ (2016) Activation of the Farnesoid X-receptor in breast cancer cell lines results in cytotoxicity but not increased migration potential. Cancer Lett 370(2):250-259. https://doi.org/10.1016/j.canle t.2015.10.031

55. Zimber A, Gespach C (2008) Bile acids and derivatives, their nuclear receptors FXR, PXR and ligands: role in health and disease and their therapeutic potential. Anticancer Agents Med Chem 8(5):540-563

56. Makishima M, Lu TT, Xie W, Whitfield GK, Domoto H, Evans RM, Haussler MR, Mangelsdorf DJ (2002) Vitamin D receptor as an intestinal bile acid sensor. Science 296(5571):1313-1316. https://doi.org/10.1126/science.1070477

57. Staudinger R, Wang X, Bandres JC (2001) Allosteric regulation of CCR5 by guanine nucleotides and HIV-1 envelope. Biochem Biophys Res Commun 286(1):41-47. https://doi.org/10.1006/ bbrc.2001.5345

58. Buscher HP, Beger M, Sauerbier H, Gerok W (1987) Bile salt shift from albumin to high-density lipoprotein in cholestasis. Hepatology 7(5):900-905

59. Centuori SM, Martinez JD (2014) Differential regulation of EGFR-MAPK signaling by deoxycholic acid (DCA) and ursodeoxycholic acid (UDCA) in colon cancer. Dig Dis Sci 59(10):23672380. https://doi.org/10.1007/s10620-014-3190-7
60. Hanafi NI, Mohamed AS, Sheikh Abdul Kadir SH, Othman MHD (2018) Overview of bile acids signaling and perspective on the signal of ursodeoxycholic acid, the most hydrophilic bile acid, in the heart. Biomolecules 8(4):159. https://doi.org/10.3390/biom8 040159

61. Craven PA, Pfanstiel J, DeRubertis FR (1987) Role of activation of protein kinase $\mathrm{C}$ in the stimulation of colonic epithelial proliferation and reactive oxygen formation by bile acids. J Clin Invest 79(2):532-541. https://doi.org/10.1172/JCI112844

62. Booth LA, Gilmore IT, Bilton RF (1997) Secondary bile acid induced DNA damage in HT29 cells: are free radicals involved? Free Radic Res 26(2):135-144

63. Glinghammar B, Inoue H, Rafter JJ (2002) Deoxycholic acid causes DNA damage in colonic cells with subsequent induction of caspases, COX-2 promoter activity and the transcription factors $\mathrm{NF}-\mathrm{kB}$ and AP-1. Carcinogenesis 23(5):839-845

64. Looby E, Abdel-Latif MM, Athie-Morales V, Duggan S, Long A, Kelleher D (2009) Deoxycholate induces COX-2 expression via Erk1/2-, p38-MAPK and AP-1-dependent mechanisms in esophageal cancer cells. BMC Cancer 9:190. https://doi. org/10.1186/1471-2407-9-190

65. Da Silva M, Jaggers GK, Verstraeten SV, Erlejman AG, Fraga CG, Oteiza PI (2012) Large procyanidins prevent bile-acid-induced oxidant production and membrane-initiated ERK1/2, p38, and Akt activation in Caco-2 cells. Free Radical Biol Med 52(1):151-159. https://doi.org/10.1016/j.freeradbiomed.2011.10.436

66. Verstraeten SV, Jaggers GK, Fraga CG (1828) Oteiza PI (2013) Procyanidins can interact with Caco- 2 cell membrane lipid rafts: involvement of cholesterol. Biochim Biophys Acta 11:2646-2653. https://doi.org/10.1016/j.bbamem.2013.07.023

67. Eisinger J, Flores J (1983) Cytosol-membrane interface of human erythrocytes: a resonance energy transfer study. Biophys J 41(3):367-379. https://doi.org/10.1016/S0006-3495(83)84448 $-8$

68. Cabral DJ, Small DM, Lilly HS, Hamilton JA (1987) Transbilayer movement of bile acids in model membranes. Biochemistry 26(7):1801-1804

69. Solvent Systems and Their Selection in Pharmaceutics and Biopharmaceutics (2007). Springer, Newyork

Publisher's Note Springer Nature remains neutral with regard to jurisdictional claims in published maps and institutional affiliations. 